UNIVERSIDADE DE SÃO PAULO

FACULDADE DE ECONOMIA, ADMINISTRAÇÃO E CONTABILIDADE PROGRAMA DE PÓS-GRADUAÇÃO EM ECONOMIA

\title{
ANÁLISE DO FUNDO CONSTITUCIONAL DE FINANCIAMENTO DO NORDESTE: UMA APLICAÇÃO DE EQUILÍBRIO GERAL COMPUTÁVEL
}

Aluno: Thiago Oliveira Nascimento Orientador: Prof. Dr. Eduardo Amaral Haddad 
Prof. Dr. Marcos Antonio Zago

Reitor da Universidade de São Paulo

Prof. Dr. Adalberto Américo Fishmann

Diretor da Faculdade de Economia, Administração e Contabilidade

Prof. Dr. Eduardo Amaral Haddad

Chefe do Departamento de Economia

Prof. Dr. Ariaster Baumgratz Chimeli

Coordenador do Programa de Pós-Graduação em Economia 
Thiago Oliveira Nascimento

\title{
ANÁLISE DO FUNDO CONSTITUCIONAL DE FINANCIAMENTO DO NORDESTE: UMA APLICAÇÃO DE EQUILÍBRIO GERAL COMPUTÁVEL
}

\author{
Dissertação apresentada ao Programa de Pós- \\ Graduação em Economia do Departamento de \\ Economia, Administração e Contabilidade da \\ Universidade de São Paulo, como requisito \\ parcial para a obtenção do título de Mestre em \\ Ciências.
}

Orientador: Prof. Dr. Eduardo Amaral Haddad

Versão Original

São Paulo 


\section{FICHA CATALOGRÁFICA}

Elaborada pela Seção de Processamento Técnico do SBD/FEA/USP

Nascimento, Thiago Oliveira

Análise do fundo constitucional de financiamento do Nordeste:

uma aplicação de equilíbrio geral computável / Thiago Oliveira Nascimento. - São Paulo, 2017.

$55 \mathrm{p.}$

Dissertação (Mestrado) - Universidade de São Paulo, 2017.

Orientador: Eduardo Amaral Haddad. 
Dedico aos meus pais, Antônio e Ângela e à minha irmã Mariana. 



\section{AGRADECIMENTOS}

Agradeço ao Cnpq, IPEA, FIPE e Fundação de Amparo à Pesquisa do Estado de São Paulo (FAPESP) pelo apoio prestado, a última pelo processo n 2015/19085-1.

Dedico esta dissertação a minha família, que me motivou a seguir este sonho de concluir o mestrado e que sempre estivaram comigo em todas as situações.

Ao meu orientador, Eduardo Haddad, eu agradeço pela orientação, paciência e dedicação. Agradeço pelo apoio durante todo o momento desde o instante em que começamos esse trabalho. Com sua convivência, cresci tanto pessoal quanto profissionalmente.

Agradeço pela colaboração do IPEA, em especial a Daniel Da Mata e Guilherme Resende, pelo apoio na pesquisa e pela oportunidade de continuar trabalhando com pessoas tão dedicadas. Além disso, me senti muito honrado pela participação no Núcleo de Economia Regional e Urbana da Universidade de São Paulo - NEREUS - no qual tive a oportunidade de conviver com professores e pessoas do mais alto nível; em especial agradeço aos professores Carlos Azzoni, Joaquim Guilhoto e André Chagas pelo apoio e dicas importantes à pesquisa. Agradeço também aos colaboradores do departamento, Pinho e Leka.

Agradeço aos professores Geoffrey Hewings e Sandy Dall'Erba por me receberem durante meu período de permanência na Universidade de Illinois.

Aos meus colegas da pós-graduação, a minha turma, ingressante de 2015 foi uma enorme satisfação e grande divertimento ter passado estes últimos anos com todos, em especial agradeço ao Fábio Tieppo Renan Alves, Arthur Viaro e Robison Francisco. Também agradeço a Vinicius Vale, Carlos Gonçalves Junior, Inácio Fernandes e Keyi Ussami pela amizade e apoio no desenvolvimento dessa pesquisa. 
"What we know is a drop, what we don't know is an ocean." Isaac Newton 



\section{RESUMO}

O Brasil tem na desigualdade regional um tema que historicamente recebe bastante atenção por parte dos pesquisadores e das formulações de políticas públicas. Regiões mais vulneráveis do país são alvos de iniciativas que tentam amenizar o problema da disparidade econômica. Dentre os instrumentos utilizados, o Fundo Constitucional de Financiamento do Nordeste (FNE) foi criado pela Constituição de 1988 com o intuito de combater as desigualdades intra e interregionais na região nordestina. O presente estudo se propõe a avaliar a eficácia do FNE como instrumento de política de combate às desigualdades regionais no Brasil aplicando uma metodologia de equilíbrio geral computável. A retirada do FNE e a realocação do montante do fundo em gastos correntes resultariam em queda no PIB e aumento da concentração da atividade e da desigualdade do PIB per capita, indicando que o FNE funcionaria como indutor de crescimento e cumpriria o objetivo de reduzir a desigualdade entre o Nordeste e o Brasil.

Palavras-chave: Economia Regional, Região Nordeste, Brasil. 



\begin{abstract}
Brazil has in regional inequality a subject that historically receives a lot of attention from the researchers and policy makers. The most vulnerable regions in Brazil received initiatives that attempt to attenuate the problem of economic disparity. Among the instruments used, the Northeastern Constitutional Financing Fund was created by the Constitution with the aim of fight against intra and interregional inequalities in the Northeastern region. The present study proposes to evaluate the efficiency of the fund as an instrument of combatant policy of regional inequalities in the Northeast region applying a methodology of computable general equilibrium. The estimation of the scenario with no existence of the fund and its reallocation in government demand implies that income and investment decreases, together with higher concentration of production and inequality of GDP per capita.
\end{abstract}

Key words: Regional Economics, Northeastern Region, Brazil. 



\section{LISTA DE ILUSTRAÇÕES}

Figura 1- Área de Atuação do Fundo Constitucional de Financiamento do Nordeste ............. 26

Figura 2 - Montante Contratado pelo FNE entre 2000 e 2013 .............................................. 27

Figura 3 - Participação Setorial Média no FNE entre 2000 e 2013 (em \%) .......................... 28

Figura 4 - Participação média por Estado no FNE entre 2000 e 2013 (em \%) ....................... 29

Figura 5 - Estrutura Aninhada da Criação de Capital no Modelo BMARIA ........................... 35

Figura 6 - Índice de Gini Locacional do PIB: Cenário de Eliminação do FNE........................ 40

Figura 7 - Índice de Williamson do PIB per capita: Cenário de Eliminação do FNE ............. 40

Figura 8 - Efeitos de Longo Prazo sobre Estoque de Capital: Cenário de Eliminação do FNE

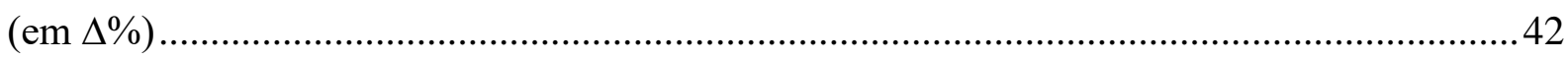

Figura 9 - Efeitos de Longo Prazo sobre População: Cenário de Retirada do FNE (em $\Delta \%$ ) .43

Figura 10 - Efeitos de Longo Prazo sobre Produto Regional Bruto: Cenário de Eliminação do

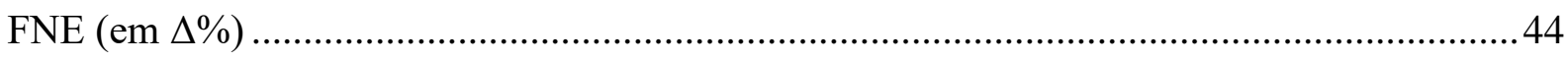

Figura 11 - Índice de Gini do PIB: Cenário de Realocação do FNE....................................... 48

Figura 12 - Índice de Williamson do PIB per capita: Cenário de Realocação do FNE............ 48 



\section{LISTA DE TABELAS}

Tabela 1 - Participação do FNE por Estado entre 2000 e 2013 (em \%) ................................ 30

Tabela 2 - Participação do FNE no Investimento em Todos os Estados Elegíveis em 2011 ..31

Tabela 3 - Percentual do FNE nos Investimentos Totais, por UF e Grande Grupo de Setores $(\mathrm{em} \%)$

Tabela 4 - Impactos de Longo Prazo sobre Variáveis Macroeconômicas: Cenário de

Eliminação do FNE (em $\Delta \%)$ 38

Tabela 5 - Variação do Nível de Atividade por Setorial Nacional: Cenário de Eliminação do FNE $(\mathrm{em} \Delta \%)$

Tabela 6 - Efeitos de Longo Prazo sobre o Estoque de Capital: Cenário de Eliminação do FNE.

Tabela 7 - Montante Repassado aos Gastos Correntes do Governo e Participações

Governamentais no PIB: Cenário de Realocação do FNE

Tabela 8 - Impactos de Longo Prazo sobre Variáveis Macroeconômicas: Cenário de realocação do FNE (em $\Delta \%)$

Tabela 9 - Impactos Comparativos sobre o PIB Nacional: Curto Prazo versus Longo Prazo.49 



\section{SUMÁRIO}

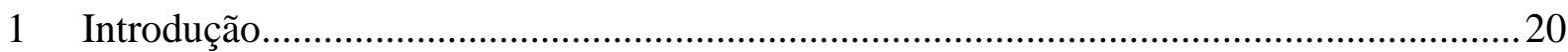

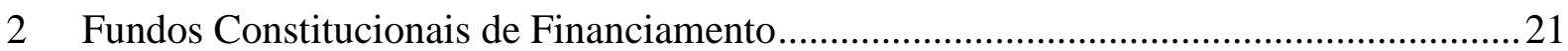

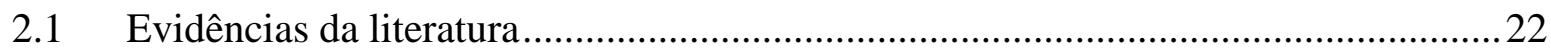

2.2 Fundo Constitucional de Financiamento do Nordeste (FNE) ...................................25

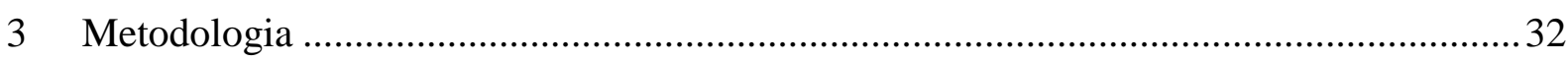

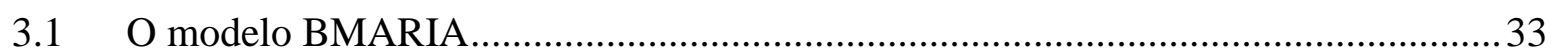

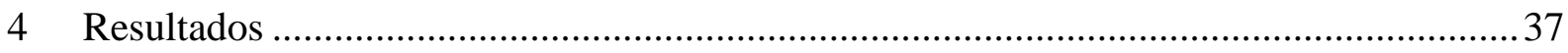

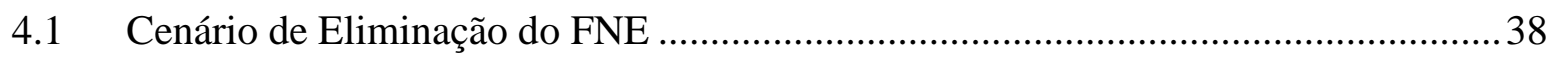

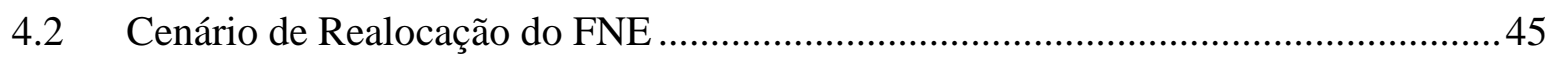

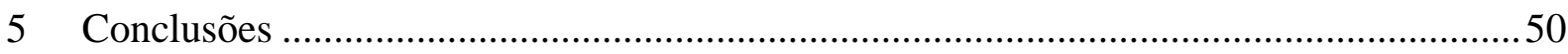

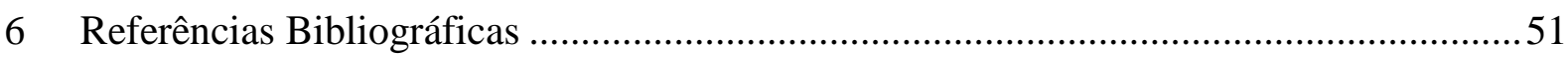





\section{Introdução}

O Brasil tem na desigualdade regional um tema que historicamente vem recebendo bastante atenção por parte dos pesquisadores e das formulações de políticas públicas. Regiões mais vulneráveis do País são alvos de iniciativas que tentam amenizar problemas de disparidades socioeconômicas. Desde a década de 1950 com o advento das Superintendências de Desenvolvimento até os recentes programas de transferência de renda, o governo adotou diversas formas de lidar com o problema, uma delas por meio de fundos constitucionais.

Criados pela Constituição de 1988, os Fundos Constitucionais de Financiamento (FC) têm por objetivo combater a desigualdade regional no Brasil e financiar o desenvolvimento local, por meio de empréstimos a taxas de juros mais acessíveis. Para tanto, três regiões foram contempladas com recursos destinados a tais fundos: Nordeste (Fundo Constitucional de Financiamento do Nordeste - FNE), Norte (Fundo Constitucional de Financiamento do Norte - FNO) e Centro-Oeste (Fundo Constitucional de Financiamento do Centro-Oeste - FCO). Trata-se atualmente do principal instrumento de combate às desigualdade entre as regiões do país e de estímulo ao desenvolvimento regional no âmbito da Política Nacional de Desenvolvimento Regional (PNDR).

A fim de se avaliar o cumprimento dos objetivos destes fundos, a literatura econômica tem debatido formas de analisar sua influência sobre o desenvolvimento econômico regional e a redução da desigualdade regional. Um instrumental bastante utilizado para a avaliação ex ante de políticas públicas são os modelos de Equilíbrio Geral Computável (EGC). Tal modelagem é uma tentativa de usar a teoria de equilíbrio geral como uma ferramenta operacional de análise de questões empíricas relacionadas à alocação de recursos e distribuição de renda nas economias de mercado. Esta abordagem é destinada a capturar os detalhes empíricos e características econômicas específicas de uma determinada economia, com o objetivo analisar os impactos de uma variedade de choques hipotéticos (Carvalho et al., 2011).

O presente estudo propõe uma aplicação de um modelo EGC inter-regional para analisar a eficácia do FNE como instrumento de combate à desigualdade regional no Brasil. No que se segue, apresentaremos, na próxima seção, uma discussão geral sobre os FCs bem como alguns aspectos específicos do FNE, tais como o montante emprestado e sua distribuição entre setores e Estados no período recente. Em seguida, faremos um breve panorama sobre a estratégia empírica adotada neste trabalho. Na seção seguinte, apresentaremos os resultados de simulações em que se considera, primeiramente, a eliminação hipotética do FNE da economia brasileira e, 
a seguir, a realocação dos recursos do Fundo, destinando-os aos gastos correntes do governo. Por fim, a última seção tece comentários finais sobre os principais resultados do trabalho. 
Ao longo da história, o processo de crescimento econômico brasileiro tem criado condições de desigualdades sociais e territoriais, que se manifestam de forma intra e interregional. Mesmo contando com mais de 3/4 do território brasileiro, as regiões mais pobres do país (Norte, Nordeste e Centro-Oeste) respondem por $42,7 \%$ da população ${ }^{1}$, mas apenas $28,1 \%$ do PIB nacional. ${ }^{2}$ Essa característica concentradora do modelo de crescimento brasileiro proporcionou a formação de uma sociedade com elevados índices de disparidade e desigualdade regionais (Oliveira e Domingues, 2005).

Com o País mais estável economicamente no fim da década de 1980, o diálogo sobre o combate às disparidades regionais voltou a ganhar força (Barros, 2011), sobretudo no advento da Constituição de 1988, quando os FCs foram criados. Assim, foi formulada uma estrutura legal para gerir tal questão: caberia ao Ministério da Integração Nacional (MI) supervisionar os Fundos de Desenvolvimento do Nordeste (FINOR) e da Amazônia (FINAN), o Departamento de obras Contra a Seca (DNOCS), a Companhia do Desenvolvimento do Vale do São Francisco (Codevasf) e os FCs, isto é, o MI passaria a fiscalizar recursos e projetos relacionados ao combate à desigualdade regional no Brasil a partir de então.

Nesse contexto, foram concebidos os FCs, um dos instrumentos que auxiliariam as políticas regionais, tendo como objetivo financiar o desenvolvimento local por meio de empréstimos a taxas de juros subsidiadas, com tratamento diferenciado para pequenos produtores. Como fazem parte de um programa de financiamento, os FCs visam o estímulo à produtividade, criação de empregos, inserção no mercado internacional, aumento na arrecadação tributária e melhoras na distribuição de renda (Ministério da Integração Nacional, 2003).

De acordo com a Lei n'. 7.827/1989, os recursos para os Fundos são oriundos de 3\% da arrecadação dos Impostos de Renda (IR) e do Imposto sobre Produtos Industrializados (IPI), além do resultado de suas aplicações. Do total arrecadado, $60 \%$ têm como destino o FNE, 20\% o FCO, e 20\% o FNO. Por sua vez, os financiamentos são concedidos por bancos financiadores: na região Norte os empréstimos são de responsabilidade do Banco da Amazônia (BASA), no Nordeste fica a cargo do Banco do Nordeste (BNB), sendo o Banco do Brasil o responsável no Centro-Oeste.

\subsection{Evidências da literatura}

\footnotetext{
${ }^{1}$ Dados do Censo de 2010 (IBGE).

${ }^{2}$ Contas regionais (IBGE).
} 
Dado seu tamanho e importância, os FCs têm recebido atenção de pesquisadores. Com objetivos de combater desigualdades regionais, há evidências que indicam que os mesmos possam estar contribuindo para a redução das disparidades entre as regiões, mesmo que os efeitos intrarregionais não apontem para uma mesma direção. Ao longo do tempo, estudos avaliaram impactos e apontaram pontos positivos e fragilidades do funcionamento dos FCs, discorrendo sobre os mecanismos de empréstimo, a falta de continuidade das políticas, sua influência sobre a produtividade das firmas, dentre outros temas.

Resende et al. (2015) fizeram um acompanhamento dos Fundos entre 1999 e 2011, separando os municípios de acordo com a tipologia adotada pela $\operatorname{PNDR}^{3}$ e, através de estimações de modelos de efeitos fixos, concluíram haver evidências de que, no Nordeste, o FNE atenua as desigualdades intrarregionais, uma vez que as tipologias de municípios de Baixa Renda e Dinâmicos apresentaram coeficientes positivos e significantes. No que se refere aos demais FCs, tal conclusão não se verificou, pois, para o FNO, as estimações indicaram efeitos positivos para o crescimento do PIB per capita para as tipologias Dinâmica e Alta Renda e, para o FCO verificou-se impacto positivo sobre o crescimento do PIB per capita nos municípios de Alta Renda do Centro-Oeste brasileiro.

Um tema relacionado refere-se à focalização espacial dos FCs. Especula-se que os empréstimos estariam concentrados em algumas regiões, sobretudo aquelas que já tenham alguma atividade econômica, ou seja, os FCs estariam sendo alocados para regiões mais ricas e não atingindo as regiões mais pobres e vulneráveis, conforme seu objetivo, o que prejudicaria o combate à desigualdade inter-regional (Oliveira e Domingues, 2005; Almeida Junior et al., 2007). Falta de informação, dificuldades de acesso à rede bancária, isolamento produtivo e carência na estrutura econômica e social local são tidos como aspectos influenciadores em tal contexto.

Nesse sentido, Monteiro (2011) avaliou a utilização dos recursos do FNO em Roraima e apontou que a distribuição espacial das concessões não segue critérios técnicos, apenas sendo regido pela demanda dos recursos, direcionando os empréstimos para projetos de maior porte, e distanciando-se, assim, do objetivo de ajudar os pequenos produtores. Ainda, o autor destacou a ineficácia do sistema bancário em liberar o total disponível, já que apenas um quarto dos recursos fora emprestado no período de análise do artigo. Para Monteiro, a baixa capilaridade de agências do BASA, a carência de bons projetos e o excesso de burocracia são elementos que

\footnotetext{
${ }^{3}$ A PNDR utiliza renda domiciliar média e crescimento do PIB per capita para a classificação dos municípios em quatro tipos: Estagnado, Baixa Renda, Dinâmica e Alta Renda.
} 
contribuíram para os resultados. Mesmo assim, verificaram-se avanços socioeconômicos, como o aumento da produção e a geração de empregos na região.

Outro exemplo é apontado por Ferreira e Mendes (2003) que analisaram o impacto do FNO sobre o setor agrícola do Pará e concluíram que o Fundo não foi indutor de desenvolvimento econômico para o setor na região, já que os empréstimos não foram acompanhados por uma política mais ampla, com fornecimento de infraestrutura e assistência aos produtores. Isso evidencia que, como tais recursos visam pequenos produtores, sejam rurais ou urbanos, os empréstimos deveriam vir acompanhados de uma estrutura mais extensa e diversificada de investimentos no ambiente econômico e em canais de comercialização para inseri-los no mercado para que houvesse um processo de desenvolvimento na região e não tentativas isoladas conforme analisado.

Além dos mecanismos de empréstimo, os impactos dos FCs sobre as firmas também receberam atenção. Carvalho et al. (2008) analisaram a influência dos Fundos na decisão locacional de firmas ao longo da década de 1990 e relataram que os FCs incentivaram o aparecimento de novas empresas nas regiões menos desenvolvidas. Além disso, os autores, apesar da ausência de evidência empírica, sugeriram que se espera um impacto com maior intensidade sobre as firmas menos produtivas, em comparação do que seria verificado com as empresas de maior porte, fazendo com que o objetivo da redução da desigualdade intrarregional possa ser atingido.

Por outro lado, Resende (2012) afirma que o FNE, mesmo estimulando o crescimento do emprego no Nordeste, não foi capaz de gerar elevação de produtividade, o que prejudicaria o crescimento de longo prazo. Em seu estudo, o autor aponta que as firmas locais não foram capazes de criar relações econômicas consistentes que gerassem melhorias na produtividade do trabalho.

Por fim, a respeito da influência dos FCs sobre o crescimento do PIB, Soares et al. (2014) avaliaram o desempenho dos municípios do Nordeste em meados da década de 2000, concluindo que os fundos não foram capazes de influenciar o crescimento das regiões com maiores e menores PIB per capita, influenciando positivamente apenas os grupos intermediários. Já Cravo et al. (2014) investigaram o impacto dos três FCs sobre o crescimento do PIB per capita durante a segunda metade da década passada e os resultados apontaram para efeitos positivos sobre o aumento do PIB per capita municipal, contudo, sem indícios de que eles tenham gerado spillovers relevantes para outros municípios.

O que se nota é que os FCs apresentam problemas em seus mecanismos, uma vez que não conseguem chegar aos produtores pobres e às regiões pobres. Além disso, a falta de 
integração produtiva entre as firmas também poderiam levar ao não espraiamento dos spillovers econômicos para as demais regiões, o que implica em uma concentração das atividades produtivas em poucos lugares, levando a um não cumprimento dos objetivos propostos. Pelo fato de ser um instrumento importante de combate à desigualdade regional, os FC's podem estar carecendo de políticas complementares que potencializem seus resultados.

\subsection{Fundo Constitucional de Financiamento do Nordeste (FNE)}

O Fundo Constitucional de Financiamento do Nordeste (FNE) atende 1982 municípios ${ }^{4}$ distribuídos entre a região Nordeste, o norte de Minas Gerais e o norte do Espírito Santo, cobrindo uma área correspondente a $21,05 \%$ do território nacional (Figura 1), que abriga uma população de mais de 56 milhões de pessoas. ${ }^{5}$ A criação do FNE foi justificada por seu potencial em auxiliar uma região que historicamente sofre com problemas sociais, econômicos e geográficos (Barros, 2011).

O Fundo tem por objetivo contribuir para o desenvolvimento econômico e social da região por meio da execução de programas de financiamento aos setores produtivos, em harmonia com o PNDR. Os recursos repassados pelo Tesouro Nacional são concedidos pelo Banco do Nordeste (BNB) e, segundo o MI, trata-se do principal instrumento de combate à desigualdade regional com foco na região Nordeste do Brasil. Como visto, do valor total arrecadado pela União para os FCs, 60\% são para o FNE e destes, metade é redirecionada para áreas prioritárias. ${ }^{6}$

\footnotetext{
${ }^{4}$ Segundo o Ministério da Integração Nacional, o FNE concedeu recursos para 99,5\% dos municípios inclusos em sua área de atuação no ano de 2013.

${ }^{5}$ Censo 2010 (IBGE).

${ }^{6}$ São consideradas áreas prioritárias o semiárido, microrregiões classificadas como Estagnadas, Baixa Renda ou Dinâmicas pela PNDR, a Grande Teresina e a região entre Juazeiro-BA e Petrolina-PE. Em 2013, R \$10,26 bilhões foram alocados para áreas prioritárias segundo a classificação da PNDR, o que representa 80,6\% do total.
} 
Figura 1- Área de Atuação do Fundo Constitucional de Financiamento do Nordeste

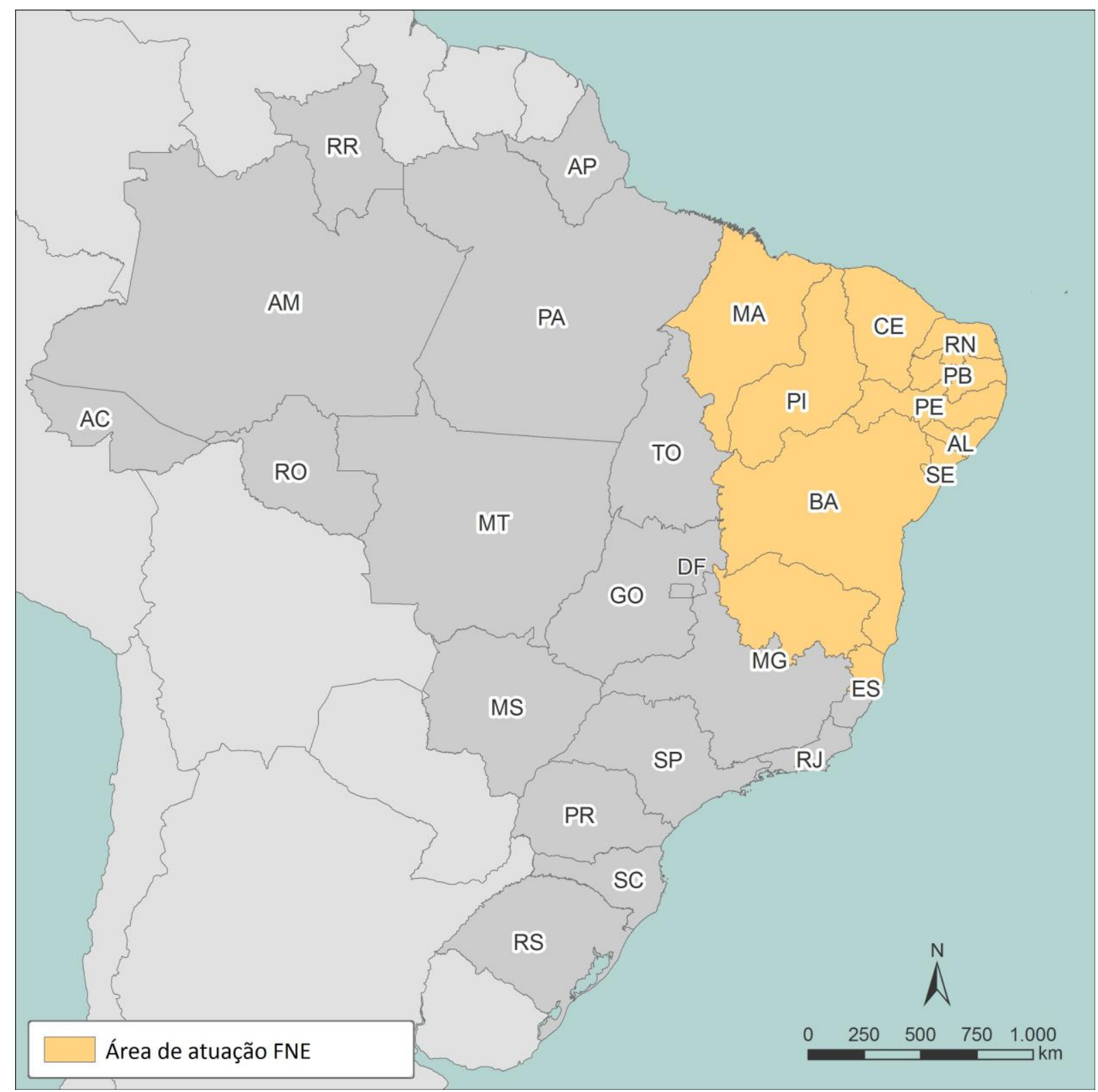

Fonte: Elaboração própria.

São passíveis de recebimento de recursos do FNE os produtores e empresas, pessoas físicas e jurídicas, além de cooperativas de produção, que desenvolvam atividades produtivas nos setores agropecuário, mineral, industrial, agroindustrial, turístico, comercial e de serviços, além de projetos de infraestrutura, inclusive com participação de empresas estatais, desde que sejam classificados como prioritários pela Superintendência de Desenvolvimento do Nordeste (SUDENE). O Fundo visa preferencialmente projetos de mini, micro e pequenos empreendedores; preservação do meio ambiente; conjugação do crédito com a assistência técnica; democratização do acesso ao crédito e apoio às atividades inovadoras. Cada setor 
passível de receber verbas do fundo se insere em linhas dos programas de financiamento, existindo nove programas setoriais ${ }^{7}$ e cinco multissetoriais. ${ }^{8}$

Vale ressaltar os volumes emprestados pelo FNE ao longo dos últimos anos (Figura 2). Com uma média de $\mathrm{R} \$ 824$ milhões por ano entre 2000 e 2013, tendo picos de mais de $\mathrm{R} \$ 10$ bilhões em 2010 e 2011, o FNE financia projetos em diversos setores, conforme a linha mais indicada. Ressalta-se ainda que, em 2009, 102 novos municípios entraram na área prioritária do Semiárido nordestino, o que ajuda a explicar o aumento dos montantes contratados nos anos seguintes.

Figura 2 - Montante Contratado pelo FNE entre 2000 e 2013 (em R $\$$ bilhões - a preços de 2010)

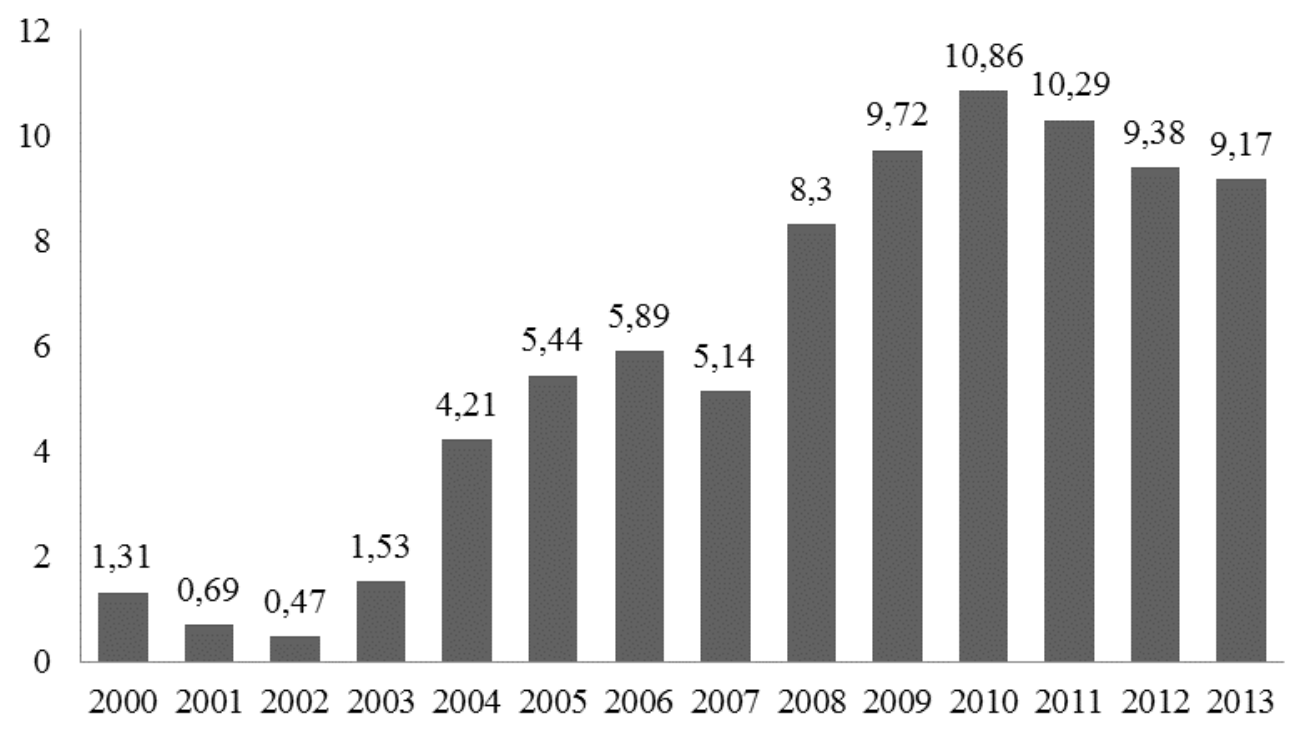

Fonte: Elaboração própria a partir de dados do BNB e IPEA.

\footnotetext{
${ }^{7}$ Programa de Fortalecimento da Agricultura Familiar (PRONAF), FNE Rural, FNE Aquipesca, FNE Frota Pesqueira, FNE Industrial, FNE Agrin, FNE Proatur, FNE Comércio e Serviços, FNE Proinfra.

${ }^{8}$ FNE Inovação, FNE-Verde, FNE Micro e Pequena Empresa, FNE EI, FNE Seca.
} 
Figura 3 - Participação Setorial Média no FNE entre 2000 e 2013 (em \%)

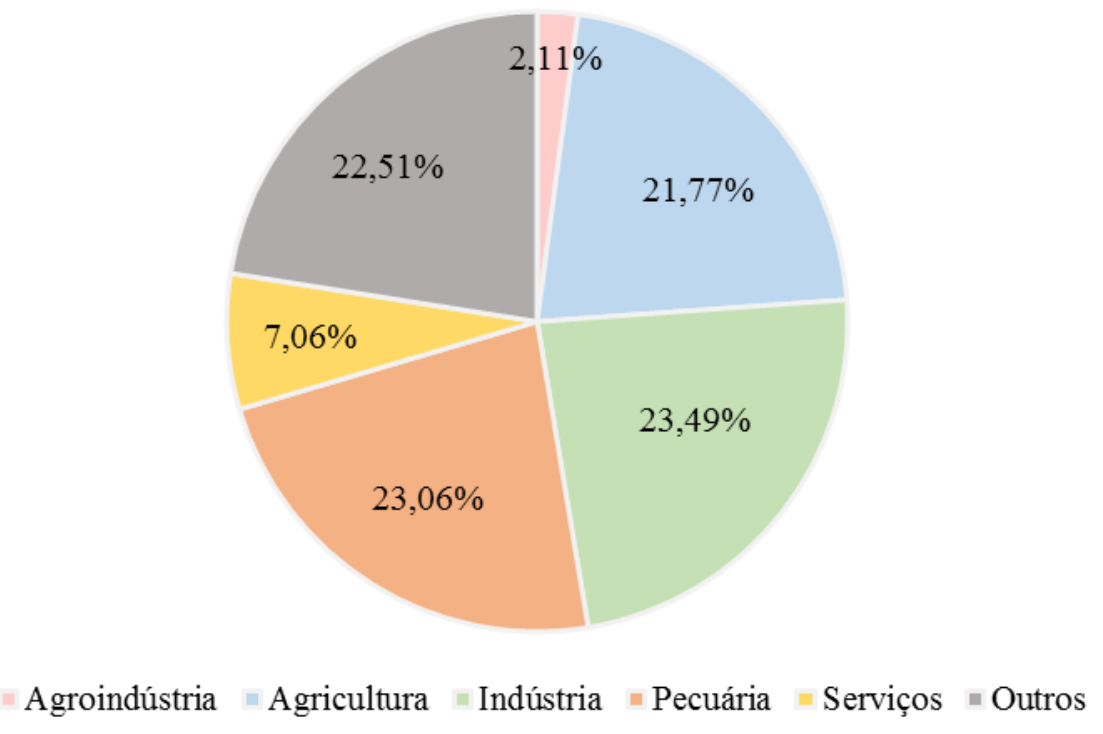

Fonte: Elaboração própria a partir de dados do BNB

O FNE tem na agricultura e na pecuária os setores com mais projetos financiados (Figura 3). Entre 2000 e 2013, estes setores foram responsáveis, em média, por 21,77\% e 23,06\%, dos valores contratados anualmente, enquanto representaram, em média, 20,61\% e 76,71\% das operações anuais. Isso é reflexo do público-alvo que mais recorre às linhas de financiamento do Fundo e dos tipos de contrato que são feitos com tais recursos, geralmente destinados a pequenos produtores agropecuários, sobretudo envolvidos com agricultura familiar. Com disso, temos o Programa de Fortalecimento da Agricultura Familiar (PRONAF) com 93,56\% das operações em 2013, quando micro e pequenos tomadores foram responsáveis por $51,4 \%$ do valor das contratações e $99,79 \%$ dos projetos.

Por outro lado, temos o setor industrial incumbido de um perfil de demandante diferente. Sendo responsável por 23,49\% do montante médio dos empréstimos entre 2000 e 2013, tal setor respondeu, em média, por $0,57 \%$ dos projetos financiados anualmente, o que se traduziu em tomadores de maior porte para essa atividade. 
Figura 4 - Participação média por Estado no FNE entre 2000 e 2013 (em \%)

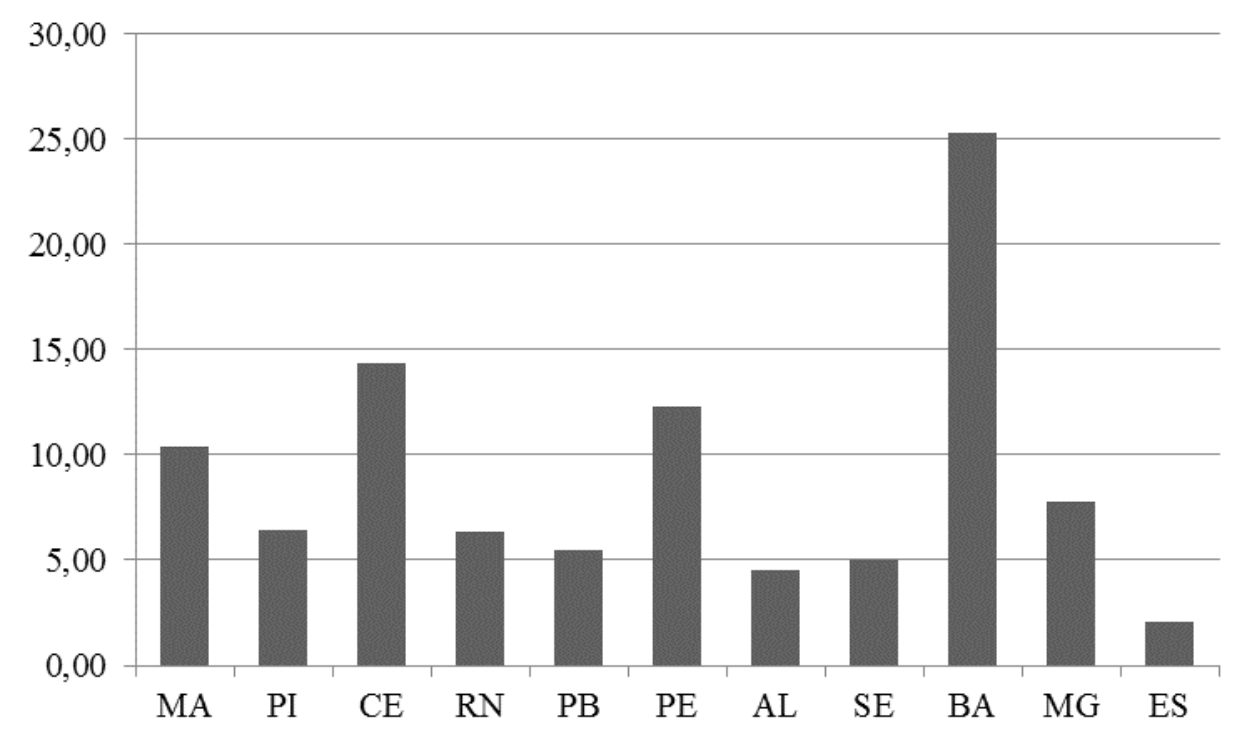

Fonte: Elaboração própria a partir de dados do BNB.

A Figura 4 mostra como o FNE foi distribuído ao longo dos anos entre os Estados receptores. Nesse caso, a Bahia representou o principal destino dos recursos do FNE, com um quarto dos empréstimos durante o período 2000-13. Destaca-se ainda o Ceará com 14,32\% do volume total de empréstimos, e Pernambuco com 12,27\%. 
Tabela 1 - Participação do FNE por Estado entre 2000 e 2013 (em \%)

\begin{tabular}{|c|c|c|c|c|c|c|c|c|c|c|c|c|c|c|c|}
\hline UF & 2000 & 2001 & 2002 & 2003 & 2004 & 2005 & 2006 & 2007 & 2008 & 2009 & 2010 & 2011 & 2012 & 2013 & Média \\
\hline Maranhão & 4,70 & 2,08 & 8,23 & 8,93 & 7,42 & 20,72 & 10,29 & 12,85 & 12,34 & 14,69 & 8,65 & 13,56 & 9,35 & 11,80 & 10,40 \\
\hline Piauí & 5,53 & 2,31 & 6,48 & 4,29 & 10,53 & 5,69 & 5,52 & 5,07 & 4,41 & 5,01 & 7,50 & 7,66 & 10,36 & 10,11 & 6,46 \\
\hline Ceará & 5,61 & 6,17 & 13,73 & 27,88 & 18,40 & 10,96 & 12,59 & 12,59 & 15,17 & 17,63 & 18,36 & 16,09 & 12,56 & 12,78 & 14,32 \\
\hline Rio Grande do Norte & 4,62 & 8,12 & 5,97 & 4,18 & 7,10 & 4,48 & 5,96 & 4,44 & 10,70 & 7,43 & 6,80 & 8,15 & 5,07 & 6,04 & 6,36 \\
\hline Paraíba & 6,46 & 5,77 & 4,46 & 6,15 & 5,99 & 4,58 & 6,71 & 6,35 & 4,71 & 6,02 & 4,95 & 4,04 & 4,99 & 5,76 & 5,50 \\
\hline Pernambuco & 13,59 & 7,11 & 5,60 & 8,22 & 11,39 & 9,16 & 11,37 & 12,13 & 14,28 & 15,04 & 15,00 & 12,63 & 22,55 & 13,75 & 12,27 \\
\hline Alagoas & 4,92 & 4,08 & 5,09 & 2,73 & 6,54 & 3,69 & 4,80 & 5,76 & 3,77 & 5,15 & 4,29 & 3,81 & 4,09 & 4,85 & 4,54 \\
\hline Sergipe & 6,62 & 6,20 & 7,47 & 6,82 & 3,92 & 3,56 & 4,73 & 4,73 & 5,20 & 4,75 & 4,07 & 3,41 & 3,83 & 4,30 & 4,97 \\
\hline Bahia & 37,58 & 3,89 & 30,47 & 26,66 & 25,21 & 29,75 & 32,99 & 29,73 & 23,36 & 19,92 & 24,51 & 25,00 & 21,02 & 24,33 & 25,32 \\
\hline Minas Gerais & 6,36 & 48,34 & 7,83 & 2,26 & 2,65 & 6,56 & 3,71 & 4,36 & 4,47 & 3,11 & 4,77 & 4,65 & 5,51 & 4,09 & 7,76 \\
\hline Espírito Santo & 4,01 & 5,93 & 4,70 & 1,89 & 0,86 & 0,84 & 1,32 & 1,99 & 1,59 & 1,25 & 1,12 & 0,99 & 0,66 & 2,18 & 2,09 \\
\hline TOTAL & 100,0 & 100,0 & 100,0 & 100,0 & 100,0 & 100,0 & 100,0 & 100,0 & 100,0 & 100,0 & 100,0 & 100,0 & 100,0 & 100,0 & 100,0 \\
\hline
\end{tabular}

Fonte: Elaboração própria a partir de dados do BNB. 
Por se tratar de recursos que financiam a capacidade produtiva, o FNE se torna um canal de investimento na região onde atua. Em 2011, ano de referência para nossas simulações, o FNE apresentou uma pequena participação no investimento nacional, com apenas $1,14 \%$ do total, sendo que os $\mathrm{R} \$ 10$ bilhões emprestados naquele ano corresponderam a 4,45\% das inversões feitas nos Estados passíveis de recebimento de recursos do Fundo (Tabela 2).

Tabela 2 - Participação do FNE no Investimento em Todos os Estados Elegíveis em 2011 (em R $\$$ bilhões)

\begin{tabular}{lccc}
\hline \multicolumn{1}{c}{ UF } & FNE & Investimento & $(\%)$ \\
\hline Maranhão & 1,67 & 10,90 & 15,29 \\
Piauí & 0,76 & 5,47 & 13,89 \\
Ceará & 1,50 & 17,08 & 8,76 \\
Rio Grande do Norte & 0,67 & 8,50 & 7,84 \\
Paraíba & 0,51 & 6,22 & 8,16 \\
Pernambuco & 1,47 & 26,20 & 5,62 \\
Alagoas & 0,46 & 6,55 & 7,03 \\
Sergipe & 0,42 & 5,77 & 7,24 \\
Bahia & 2,13 & 36,34 & 5,85 \\
Minas Gerais & 0,60 & 88,94 & 0,67 \\
Espírito Santo & 0,12 & 19,06 & 0,62 \\
Área FNE & 10,29 & 231,03 & 4,45 \\
\hline Fonte: Elaboração própria a partir dos dados do BNB e IPEA.
\end{tabular}

Nota-se que o Maranhão foi a Unidade Federativa (UF) em que houve a maior contribuição do Fundo nos investimentos totais do Estado (15,29\%), seguido proximamente do Piauí (13,89\%). Até pelo fato de apenas parte de seus territórios receberem recursos do FNE, Minas Gerais $(0,67 \%)$ e Espírito Santo $(0,62 \%)$ têm no FNE pequenas participações nos investimentos estaduais. 


\section{Metodologia}

Como visto na seção anterior, os estudos empíricos sobre os FCs têm considerado cada vez mais a dimensão espacial das atividades econômicas. Além disso, as pesquisas mais recentes têm destacado outra questão relevante relacionada às disparidades regionais, muito presentes em uma economia de grandes extensões territoriais como a brasileira. A densidade econômica de uma região mais desenvolvida proporciona oportunidades que não poderiam ser concretizadas por firmas similares localizadas em lugares com economias menos diversificadas. Isso faz com que existam discrepâncias nas vantagens comparativas - originadas de sua localização central não apenas em termos geográficos, mas também em termos econômicos -, que poderiam ser potencialmente alteradas por políticas públicas que visem influenciar as forças que regem a dinâmica espacial da economia (Haddad e Azzoni, 2001).

Com o objetivo de se avaliar o FNE, seria desejável a utilização de um ferramental teórico-empírico que nos permitisse captar as especificidades da economia em um contexto de um sistema inter-regional integrado. Uma das ferramentas disponíveis para se investigar questões como as discutidas anteriormente são os modelos inter-regionais EGC (IEGC). Modelos IEGC são considerados de equilíbrio geral, pois especificam mercados interdependentes, em que os valores de equilíbrio de todas as variáveis são determinados simultaneamente; e são inter-regionais, uma vez que consideram mercados com localizações específicas no espaço. Nesta roupagem teórica, os agentes respondem de forma ótima a variações na economia oriundas de choques exógenos.

Algumas vantagens metodológicas podem ser associadas à abordagem IEGC em sua utilização em nosso exercício: teoricamente, é possível resolver problemas não lineares, estimar preços endogenamente, incorporar múltiplos mercados, considerar várias simulações de políticas, analisar a estrutura da economia, analisar efeitos diretos e indiretos, incluir restrições ou variáveis estruturais específicas que reflitam mais realisticamente a realidade da região em questão, incorporar competição imperfeita em todos ou em alguns mercados, quantificar eficiência econômica e impactos distributivos e sociais simultaneamente (Cardenete e Delgado, 2013).

Já pelo lado empírico, estudos de impacto se mostram mais precisos e específicos, uma vez que podemos abordar questões intrínsecas no que diz respeito a impactos regionais, setoriais ou sobre o bem-estar das famílias. Além disso, somos capazes de representar uma visão ampla da economia, com base no fluxo de equilíbrio dos mercados dos fatores de produção, em termos reais e nominais, visto que a abordagem de equilíbrio geral visa modelar todas as relações 
existentes na economia que representam as transações monetárias e de bens, em contraste com a abordagem de equilíbrio parcial, que analisa os diferentes setores de uma forma isolada, em condições ceteris paribus (Fortuna et al., 2014; Menezes et al., 2006).

A fim de se avaliar a importância de um dos FCs para a economia brasileira, faremos uma aplicação de um modelo IEGC. Em nossas simulações, supomos que o montante emprestado pelo FNE seja destinado a investimentos produtivos. Esta hipótese de trabalho considera os objetivos do Fundo, seus mecanismos de operação e público alvo. Por se tratar de um empréstimo, presume-se que os recursos sejam direcionados à expansão da capacidade produtiva, hipótese também utilizada nas avaliações de impacto elaboradas pelo Banco do Nordeste. $^{9}$

\subsection{O modelo BMARIA ${ }^{10}$}

As simulações dos impactos do FNE utilizarão o modelo BMARIA ${ }^{11}$, um modelo IEGC para simulações de estática comparativa dentro da economia brasileira. Além dos aspectos já mencionados, os fluxos de comércio entre as regiões serão de grande importância em nossos exercícios. As ligações inter-regionais são movidas por relações econômicas, evidenciadas não apenas por meio de fluxos comerciais, mas também pela mobilidade de fatores de produção no espaço (Haddad, 2004). Para incorporar tais características do sistema inter-regional brasileiro, o modelo BMARIA considera explicitamente os fluxos comerciais entre pares de origem e destino disponibilizados por uma da matriz inter-regional de insumo produto, bem como considera a possibilidade de migração de mão-de-obra entre as regiões e re-localização marginal das atividades por meio de decisões de investimentos no longo prazo (Haddad, 1999; Haddad, 2004). Isso permite uma melhor caracterização da heterogeneidade do espaço e uma melhor abordagem das questões de assimetria subjacentes.

A versão do modelo B-MARIA utilizada neste trabalho reconhece 27 regiões domésticas e uma região externa. As regiões domésticas são compostas pelas 27 UFs brasileiras. As transações com o exterior são modeladas a partir de transações com uma única região externa. Há nove setores e nove produtos. O modelo reconhece ainda dois insumos primários utilizados na atividade produtiva, capital e trabalho, e sete categorias de uso: consumo intermediário, demanda por investimento, consumo das famílias, exportação, consumo dos governos regionais, consumo do Governo Federal e as variações de estoque. Os bens comércio e

\footnotetext{
${ }^{9}$ Sabe-se, contudo, que parte dos empréstimos é destinada ao financiamento de capital de giro.

${ }^{10}$ Esta seção baseia-se em Campos e Haddad (2016).

${ }^{11}$ Para mais detalhes acerca do modelo BMARIA, ver Haddad (1999), Haddad (2004) e Peter et al. (1996).
} 
transporte são tratados como bens-margem. Adota-se ainda a hipótese de concorrência perfeita em todos os mercados. ${ }^{12} \mathrm{O}$ modelo encontra-se calibrado para o ano de 2011.

O modelo utilizado no presente trabalho possui 756.189 equações e 787.141 variáveis. Desta forma, torna-se necessário, para a solução do mesmo, determinar exogenamente 30.952 variáveis. A escolha de quais variáveis devem ser determinadas exogenamente tem, no entanto, impacto direto sobre os resultados da simulação e, assim, as mesmas devem ser cuidadosamente selecionadas de sorte a mimetizar ambientes econômicos desejados. No presente trabalho, realizaremos simulações tendo por fim analisar o impacto do FNE no longo prazo. A principal diferença entre o curto prazo e o longo prazo está relacionada à mobilidade intersetorial e interregional da mão de obra e do capital.

No fechamento de longo prazo pressupõe-se que a mão de obra possa se movimentar entre as regiões do modelo. Ademais, adota-se a hipótese que os agentes decidem se realocar para regiões que apresentam maiores aumentos no bem-estar individual, fazendo com que, em equilíbrio, todas as regiões apresentem a mesma variação na utilidade do agente individual. Assim, os salários nominais serão ajustados de sorte a equilibrar a oferta e a demanda em cada região, gerando alterações nos salários reais regionais. Em relação ao mercado de capitais, pressupõe-se que o investimento setorial em cada região seja determinado pela taxa de retorno do investimento em bens de capital. Neste contexto, os investidores percebem como benefício da produção de bens de capital o valor recebido pelo aluguel do capital, enquanto que o custo associado ao mesmo é o custo da produção de unidades de capital. Assim sendo, o retorno da produção de bens de capital é a razão entre o aluguel recebido por unidade de capital e o custo de sua produção. Em virtude do exposto, o investimento em determinado setor aumenta com a elevação no valor do aluguel naquele setor ou com a redução nos custos de produção de unidades de capital.

O módulo de criação de capital no modelo B-MARIA é de especial interesse para nossas simulações. Nesse módulo, os investidores minimizam custos sujeitos a uma estrutura tecnológica aninhada a fim de se combinar os diversos bens da economia na criação de uma unidade-padrão de capital em um determinado setor em uma determinada região.

\footnotetext{
${ }^{12}$ A família de modelos oriundos do modelo B-MARIA (Haddad, 1999), encontra-se documentada em diversos estudos. Informações adicionais sobre os modelos da família B-MARIA podem ser encontrados em Haddad e Hewings (2005), Haddad (2004) e Haddad et al. (2008).
} 
Figura 5 - Estrutura Aninhada da Criação de Capital no Modelo BMARIA

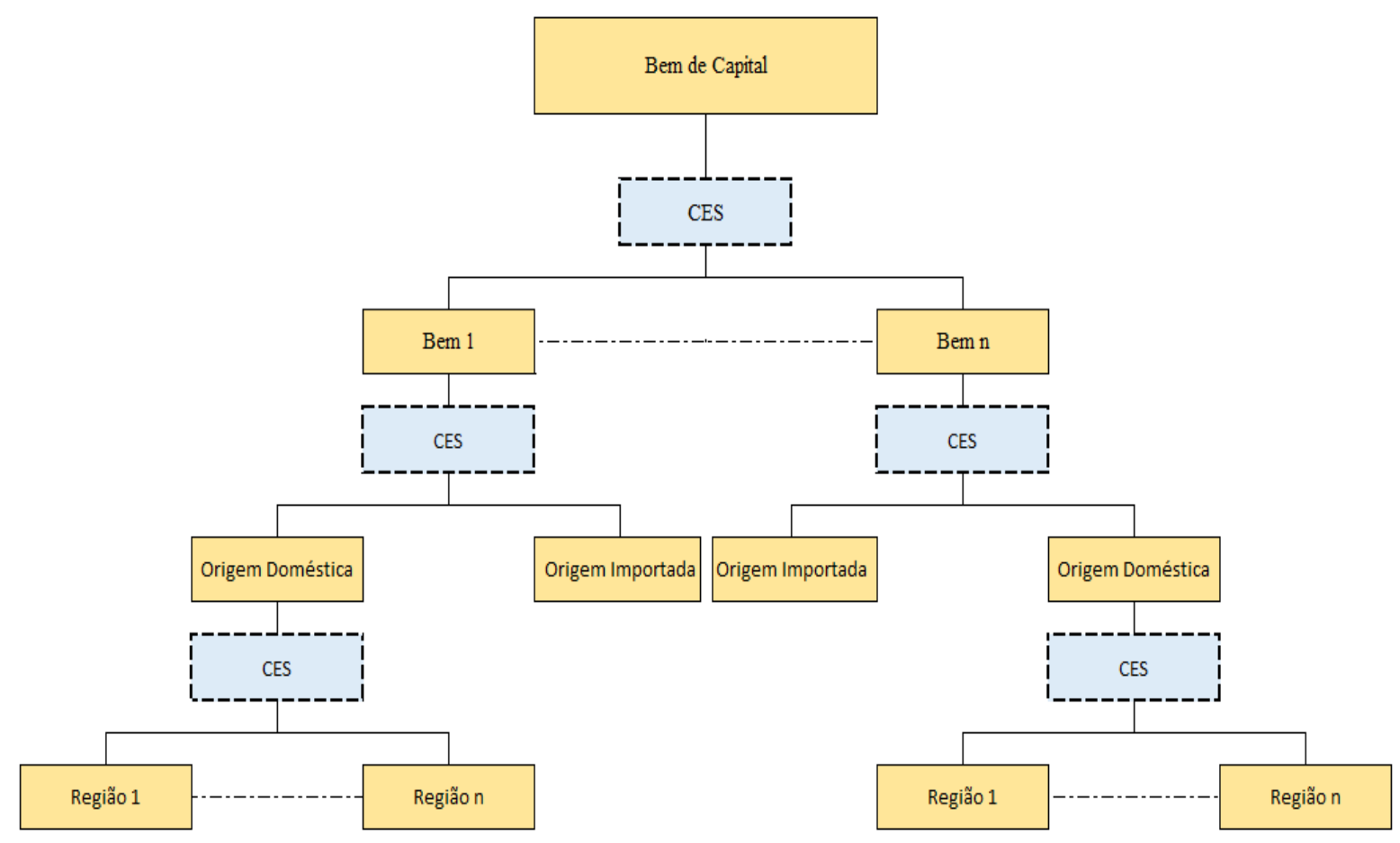

Fonte: Elaboração própria.

A modelagem do investimento busca justamente captar os efeitos de choques na alocação do gasto de investimento entre setores e regiões (Porsse, 2005). Note que a formação de capital demanda bens domésticos e importados e não há utilização direta de fatores primários, embora eles sejam usados indiretamente, uma vez que cada bem requer sua parcela de fatores para a sua produção. No terceiro nível da estrutura aninhada, funções CES substituem imperfeitamente os bens de diferentes regiões a fim de se formar o bem composto nacional e este também seja substituído imperfeitamente com bens importados através de uma função de elasticidade constante. No nível superior, uma função CES garante a substituição imperfeita entre os diferentes bens para a formação da unidade de capital.

Para a construção dos nossos cenários, consideramos como referência as aplicações de modelos EGC utilizados dos Fundos Estruturais e de Investimento Europeus (ÁlvarezMartínez, 2014). Os mecanismos de operação da política brasileira se assemelham à forma pela qual a iniciativa europeia atua, uma vez que em ambos os casos se objetiva o desenvolvimento regional por meio de financiamentos de projetos a taxas de juros subsidiadas e contando com áreas prioritárias, que se beneficiam de maior disponibilidade de recursos para empréstimos. Em suas simulações, Álvarez-Martínez (2014) avaliou os impactos do Fundo Europeu por meio 
de sua eliminação hipotética ${ }^{13}$, estratégia também adotada neste estudo. Uma vez que o Fundo estimula a expansão produtiva através da expansão de capital, nossas simulações utilizarão um fechamento de longo prazo, descrito acima.

13 Carvalho et al. (2011) também fazem simulações de retiradas graduais do fundo. 


\section{Resultados}

Nossa estratégia de simulação dos efeitos do FNE considera duas etapas. Na primeira, eliminamos o FNE da economia, analisando os efeitos desta extração hipotética dos fluxos de investimentos associados à alocação dos empréstimos entre setores e estados. Na segunda etapa, realocamos os valores do Fundo para outra finalidade: consideramos que os recursos são gastos pelo governo obedecendo à mesma estrutura média de gastos entre as UFs.

Para a implementação do primeiro cenário, retiramos da matriz de dados a parte dos fluxos de investimento (FBCF) de responsabilidade do Fundo, tomando como base a média de empréstimos concedidos entre 2000 e 2011. Isso funcionaria como se deslocássemos para a esquerda a curva de demanda por investimentos, uma vez que retiramos do sistema uma parte do montante observado. Para definirmos as reduções específicas na demanda por investimentos, agrupamos os setores do modelo em quatro grandes grupos: S1 (agropecuária); S2 (agroindústria); S3 (outras indústrias e construção) e S4 (comércio, transporte e outros serviços). Para cada setor dentro de cada grupo, assume-se o mesmo percentual do FNE dentro do investimento, conforme Tabela $3 .^{14}$

Tabela 3 - Percentual do FNE nos Investimentos Totais, por UF e Grande Grupo de Setores $(\mathrm{em} \%)$

\begin{tabular}{lcccc}
\hline \multicolumn{1}{c}{ UF } & S1 & S2 & S3 & S4 \\
\hline Maranhão & 17,99 & 35,57 & 5,23 & 0,75 \\
Piauí & 1,88 & 29,98 & 2,53 & 1,04 \\
Ceará & 3,26 & 15,95 & 11,13 & 1,39 \\
Rio Grande do Norte & 3,10 & 28,66 & 3,17 & 0,76 \\
Paraíba & 4,91 & 19,95 & 8,39 & 0,90 \\
Pernambuco & 2,53 & 11,74 & 5,12 & 0,45 \\
Alagoas & 7,62 & 5,75 & 8,00 & 0,71 \\
Sergipe & 39,53 & 21,87 & 3,65 & 1,40 \\
Bahia & 1,93 & 18,60 & 3,69 & 0,58 \\
Minas Gerais & 0,06 & 4,01 & 0,05 & 0,03 \\
Espírito Santo & 7,69 & 15,26 & 0,05 & 0,08 \\
\hline Fonte: Elaboração própria & & & &
\end{tabular}

${ }^{14}$ SIUP e administração pública não foram considerados. 


\subsection{Cenário de Eliminação do FNE}

A Tabela 4 apresenta os efeitos da simulação de longo prazo dos impactos da eliminação dos fluxos de investimentos associados ao FNE sobre variáveis macroeconômicas selecionadas. Em nossa estimação, a eliminação do FNE resultaria em uma redução do PIB real equivalente a 0,19\%, um montante de $\mathrm{R} \$ 41,45$ bilhões em relação ao observado no ano de 2011. Além disso, verifica-se uma queda nos preços gerais da economia de 0,41\%. As famílias também sofreriam perda de bem estar com essa situação, uma vez que os resultados para o consumo real apontam uma redução de 0,47\% em comparação ao ocorrido no ano base de 2011, o equivalente a $\mathrm{R} \$ 21,42$ bilhões. Os investimentos também se mostram sensíveis em relação à eliminação do FNE, apresentando uma redução de $0,39 \%$ em termos reais.

Tabela 4 - Impactos de Longo Prazo sobre Variáveis Macroeconômicas: Cenário de Eliminação do FNE (em $\Delta \%$ )

\begin{tabular}{lr}
\hline \multicolumn{1}{c}{ Variável } & $(\Delta \%)$ \\
\hline PIB real & $-0,19$ \\
Consumo real das famílias & $-0,47$ \\
Gastos reais com investimento & $-0,39$ \\
Volume de exportações & 0,79 \\
Volume de importações & $-0,67$ \\
Índice de preços do PIB & $-0,41$ \\
\hline Fonte: Elaboração própria. &
\end{tabular}

Em relação ao comércio internacional, observa-se uma queda nas importações de 0,67\%, enquanto as exportações cresceriam 0,79\%, em comparação aos dados de 2011. Uma explicação para essa melhora na balança comercial se deve ao fato de que a eliminação do FNE geraria uma realocação da demanda, sobretudo saindo do Nordeste em direção às outras regiões. Com isso, as firmas tenderiam a substituir o que era vendido aos nordestinos para outros clientes, externos nesse caso, o que implicaria na alta das exportações.

Acompanhando a redução do PIB, quase todos os setores apresentariam uma queda no seu nível de atividade, sobretudo a agropecuária, com encolhimento de $0,40 \%$. Por outro lado, na indústria haveria um aumento de $0,14 \%$ do nível de atividade, mesmo o setor sendo responsável por uma boa porção das contratações do FNE. A realocação da produção industrial saindo do Nordeste para outras regiões explicaria este efeito agregado. 
Tabela 5 - Variação do Nível de Atividade por Setorial Nacional: Cenário de Eliminação do $\mathrm{FNE}(\mathrm{em} \Delta \%)$

\begin{tabular}{lc}
\hline \multicolumn{1}{c}{ Setor } & $(\Delta \%)$ \\
\hline Agropecuária & $-0,40$ \\
Agroindústria & $-0,29$ \\
Outras indústrias & 0,14 \\
SIUP & $-0,26$ \\
Construção & $-0,07$ \\
Comércio & $-0,19$ \\
Transporte & $-0,12$ \\
Adm. Pública & $-0,02$ \\
Outros serviços & $-0,17$ \\
\hline
\end{tabular}

Fonte: Elaboração própria.

Tendo em vista que o FNE busca a diminuição da desigualdade regional entre o Nordeste e o restante do país via crescimento econômico, para entender melhor o cumprimento deste objetivo do Fundo seria importante analisar o que aconteceria com a concentração do PIB e a desigualdade do PIB per capita entre as regiões, com a ausência dos recursos do Fundo investidos na região Nordeste. Para a análise dos efeitos sobre a concentração da produção, utilizamos o Índice de Gini locacional do PIB $^{15}$, enquanto o Índice de Williamson do PIB per capita $^{16}$ é computado para analisarmos os efeitos sobre a desigualdade regional.

Com a eliminação dos recursos do Fundo, a produção no Brasil seria mais concentrada, uma vez que o Índice de Gini Locacional do PIB apresentaria um valor mais alto (Figura 6). A elevação do Índice de Williamson para o PIB per capita (Figura 7) revela uma dispersão maior dessa variável em relação à média, indicando aumento da desigualdade regional com a eliminação do FNE. Tais resultados sugerem que o Fundo atua de forma a desconcentrar a produção e mantê-la menos desigual ao longo do território nacional.

15 O Gini locacional do PIB (G) calcula a concentração espacial da produção. Pode ser obtido pelas seguintes fórmulas:

$$
\begin{gathered}
\beta=\sum_{i}\left(P_{i}-P_{i-1}\right)\left(\frac{X_{i}-X_{i-1}}{2}\right) \\
\alpha=0,5-\beta \\
G=2 \alpha
\end{gathered}
$$

Onde: $P_{i}$ é a proporção acumulada da razão entre o valor do PIB na região i e o PIB no país, após a organização das produções regionais em ordem crescente e $X_{i}$ é a proporção acumulada da razão entre uma região e o número de regiões no país.

${ }^{16} \mathrm{O}$ Índice de Williamson do PIB per capita (W) seguiu a seguinte fórmula:

$$
W=\frac{\sqrt{\sum_{i}\left(y_{i}-\bar{y}\right)^{2} \frac{n_{i}}{N}}}{\bar{y}}
$$

Onde: $y_{i}$ é o PIB per capita da região i; $\bar{y}$ é o PIB per capita nacional; $n_{i}$ é a população da região i e $N$ é a população do país. 
Figura 6 - Índice de Gini Locacional do PIB: Cenário de Eliminação do FNE 0,5885

0,5880

0,5875

0,5870

0,5865

0,5860

0,5855

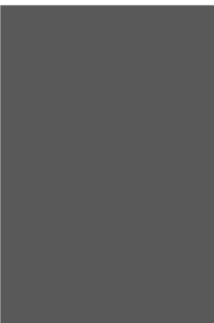

Cenário Base

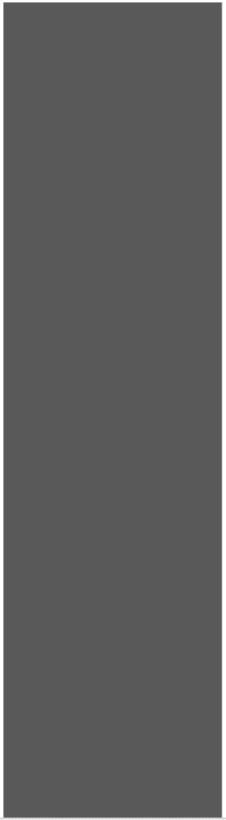

Retirada do fundo

Fonte: Elaboração própria.

Figura 7 - Índice de Williamson do PIB per capita: Cenário de Eliminação do FNE 0,4300

0,4295

0,4290

0,4285

0,4280

0,4275

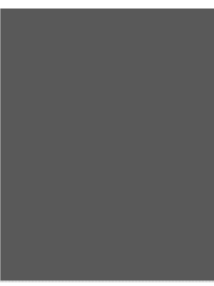

Cenário Base

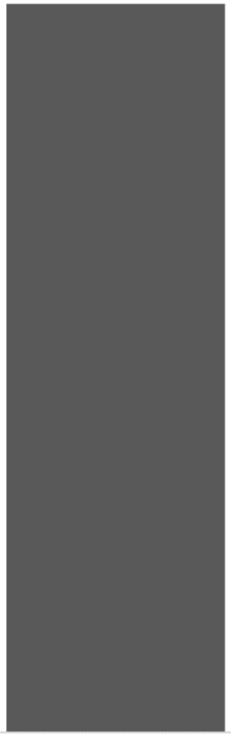

Retirada do fundo

Fonte: Elaboração própria. 
No longo prazo, o fator capital é livre para se mover entre setores e regiões a fim de se ajustar aos diferenciais de taxas de retorno. A seguir, apresentamos os efeitos desse processo de mobilidade sobre a re-localização do estoque de capital (Tabela 6 e Figura 8). Ressalta-se que estes movimentos servem como mecanismos de ajustamento do modelo ao choque no ambiente de longo prazo.

Tabela 6 - Efeitos de Longo Prazo sobre o Estoque de Capital: Cenário de Eliminação do FNE

\begin{tabular}{lcc}
\hline \multicolumn{1}{c}{ UF } & $\begin{array}{c}\text { Montante } \\
(\mathrm{R} \$ \text { milhões })\end{array}$ & $(\Delta \%)$ \\
\hline Rondônia & 15,04 & 0,02 \\
Acre & $-21,86$ & $-0,10$ \\
Amazonas & $-238,32$ & $-0,15$ \\
Roraima & $-29,99$ & $-0,17$ \\
Pará & 636,55 & 0,26 \\
Amapá & $-31,56$ & $-0,13$ \\
Tocantins & $-11,18$ & $-0,03$ \\
Maranhão & $-5.603,10$ & $-4,55$ \\
Piauí & $-1.070,59$ & $-1,72$ \\
Ceará & $-8.641,45$ & $-4,12$ \\
Rio Grande do Norte & $-2.109,97$ & $-2,16$ \\
Paraíba & $-2.526,67$ & $-2,86$ \\
Pernambuco & $-4.738,45$ & $-1,89$ \\
Alagoas & $-2.788,03$ & $-3,65$ \\
Sergipe & $-3.494,14$ & $-5,01$ \\
Bahia & $-6.365,04$ & $-1,63$ \\
Minas Gerais & 604,83 & 0,06 \\
Espírito Santo & $-834,09$ & $-0,36$ \\
Rio de Janeiro & 497,48 & 0,04 \\
São Paulo & $-2.540,82$ & $-0,08$ \\
Paraná & 419,56 & 0,07 \\
Santa Catarina & 476,10 & 0,12 \\
Rio Grande do Sul & 33,65 & 0,01 \\
Mato Grosso do Sul & 279,06 & 0,22 \\
Mato Grosso & 535,52 & 0,32 \\
Goiás & $-8,03$ & 0,00 \\
Distrito Federal & $-854,33$ & $-0,24$ \\
\hline Fonte: Elaboração própria. & & \\
& & \\
Pán & &
\end{tabular}


Figura 8 - Efeitos de Longo Prazo sobre Estoque de Capital: Cenário de Eliminação do FNE $(\mathrm{em} \Delta \%)$

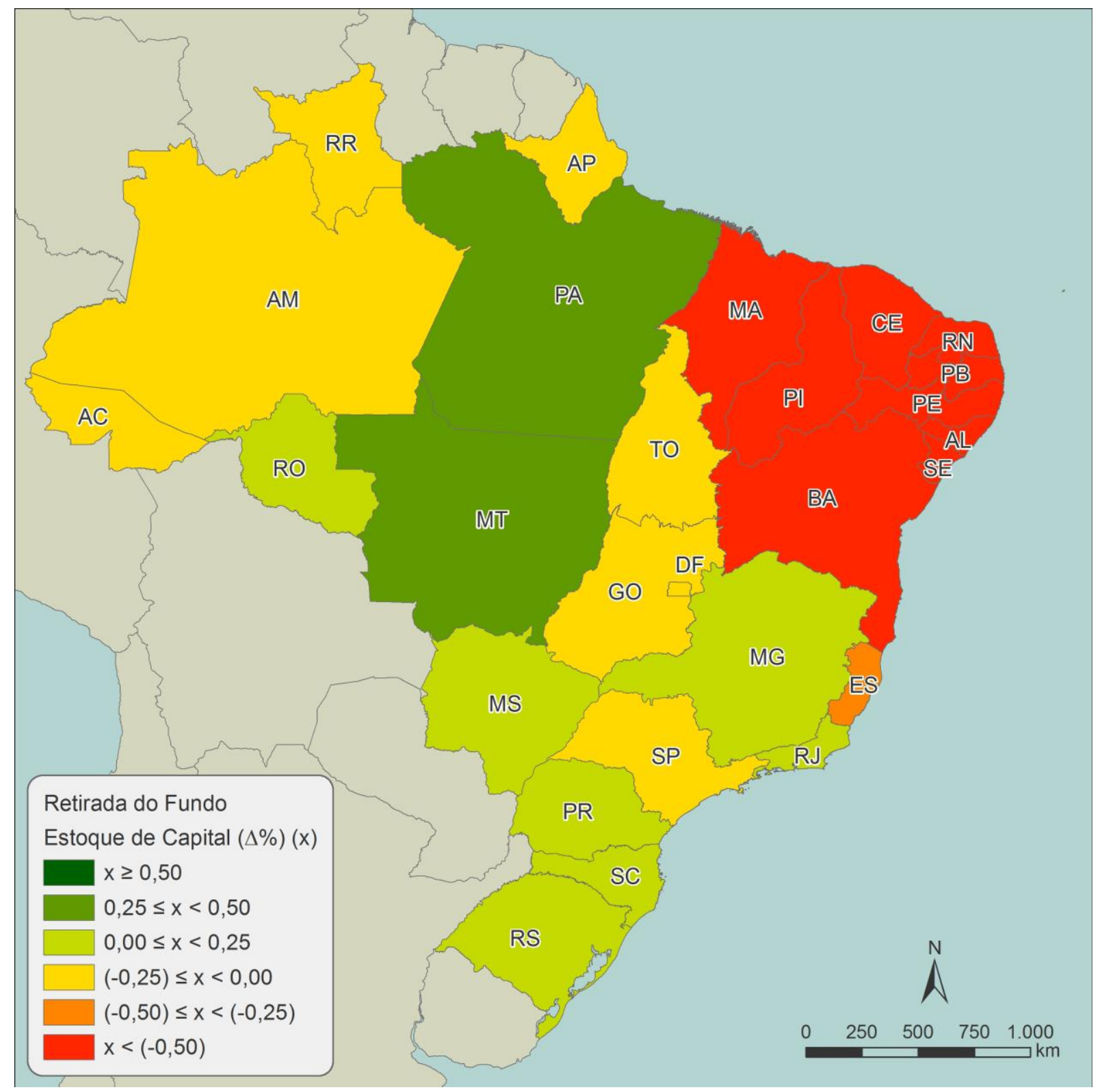

Fonte: Elaboração própria.

Os resultados apontam que a eliminação do FNE dos investimentos resultaria em uma perda de capital para os estados do nordestinos avaliada em $\mathrm{R} \$ 3,73$ bilhões em comparação ao estoque de capital estimado em 2011. Sergipe (5,01\%), Maranhão (4,55\%) e Ceará (4,12\%) seriam os estados mais sensíveis a tal situação. Em contrapartida, verificar-se-ia uma elevação do estoque de capital na região Sul equivalente a $\mathrm{R} \$ 929,31$ milhões, sendo que, em termos relativos, Mato Grosso (0,32\%), Pará (0,26\%) e Mato Grosso do Sul (0,22\%) seriam os principais beneficiados por uma potencial re-localização marginal das atividades. 
Figura 9 - Efeitos de Longo Prazo sobre População: Cenário de Retirada do FNE (em $\Delta \%$ )

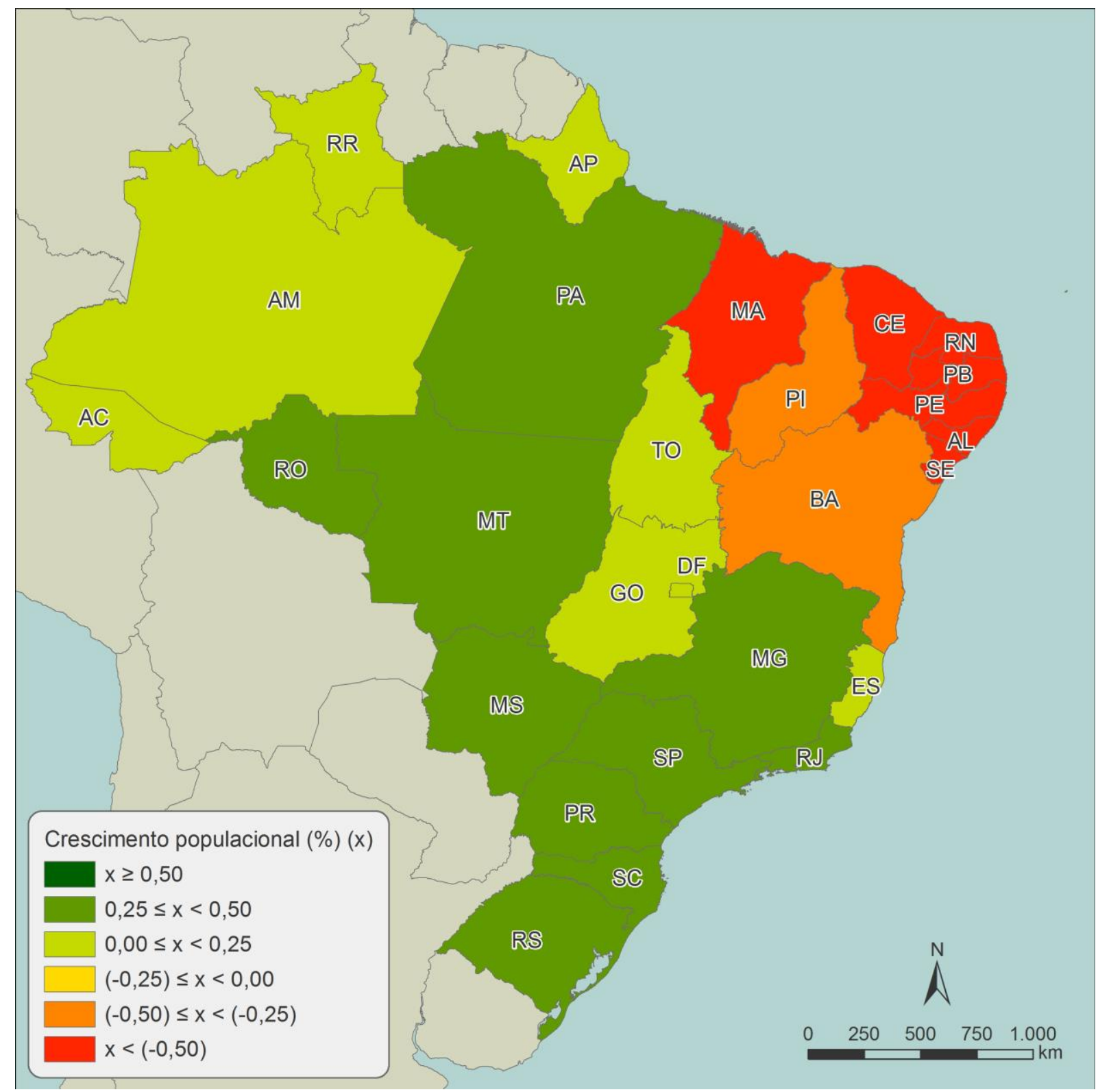

Fonte: Elaboração própria.

Ao se analisar a nova distribuição populacional após o ajustamento ao choque de eliminação dos investimentos associados ao FNE, verifica-se que o Fundo possui o papel de coibir a migração de pessoas da região Nordeste para o restante do país. Com a eliminação do Fundo, haveria maior incentivo econômico para que residentes dos estados do Nordeste migrassem para outras partes do País, majoritariamente em direção ao Centro-Sul. Sergipe ($1,49 \%)$ e Maranhão $(-1,27 \%)$ seriam os estados potencialmente mais afetados, enquanto Santa 
Catarina $(0,42 \%)$ e Paraná $(0,42 \%)$ seriam aqueles que mais verificariam maiores aumentos populacionais.

Figura 10 - Efeitos de Longo Prazo sobre Produto Regional Bruto: Cenário de Eliminação do FNE $(\mathrm{em} \Delta \%)$

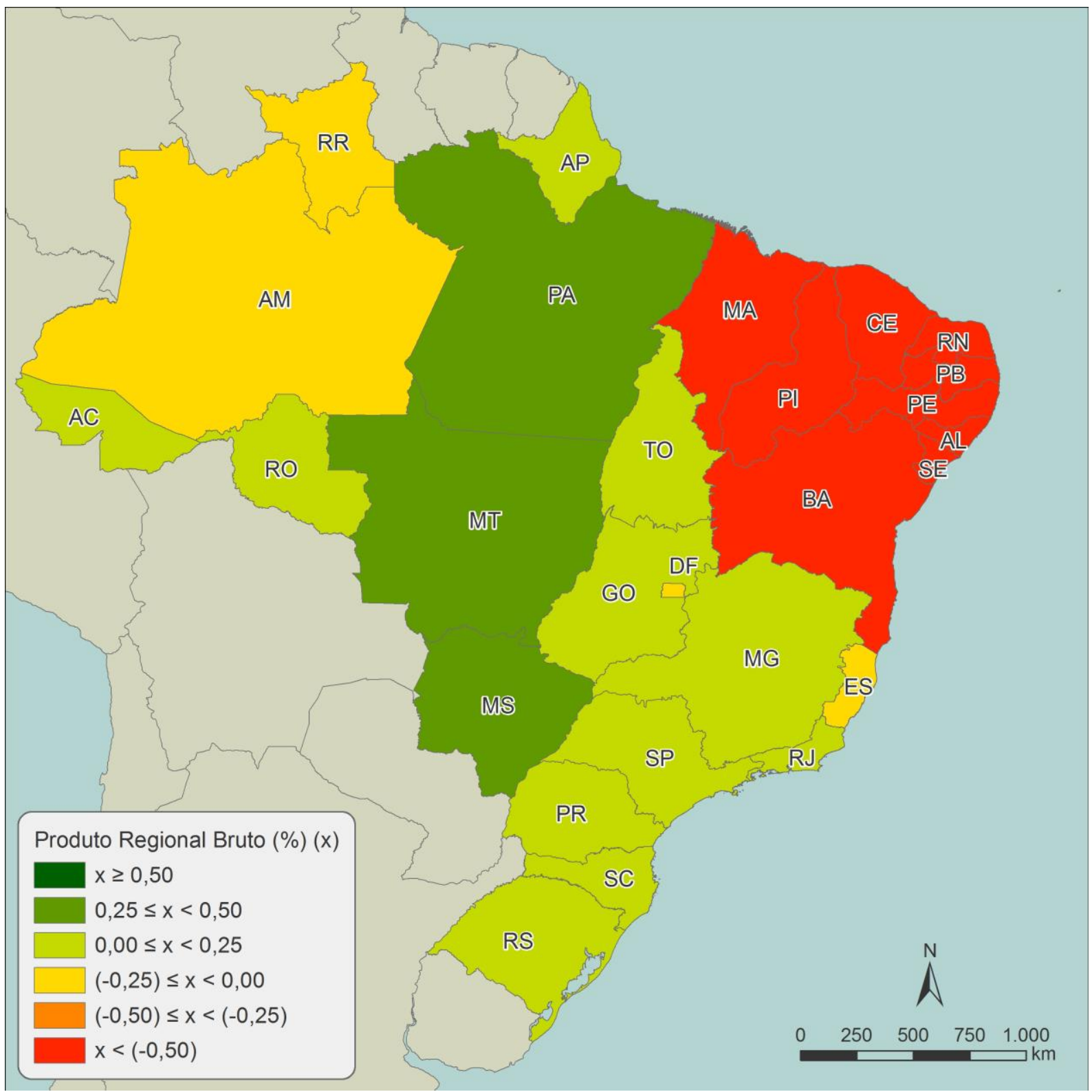

Fonte: Elaboração própria.

Como visto, ao se eliminar o FNE, a concentração do PIB seria maior que a observada no ano base, uma vez que todos os estados do Nordeste sofreriam com quedas em sua produção, todas superiores a $1 \%$, resultando em uma perda regional de $\mathrm{R} \$ 6,5$ bilhões em comparação aos valores observados em 2011. 
Com a diminuição de atividade no Nordeste, notam-se ganhos em outras UFs, sobretudo no Mato Grosso, Mato Grosso do Sul e Pará. Nas demais UFs, observa-se relativa estabilidade.

\subsection{Cenário de Realocação do FNE}

E se os recursos do FNE destinados a empréstimos para atividades produtivas regionais fossem destinados para outra finalidade? Para responder esta pergunta, a próxima simulação abordará uma forma de se calcular o custo de oportunidade do atual mecanismo de operação do FNE como instrumento do governo de combate às desigualdades regionais via expansão do investimento na região Nordeste. Neste exercício, além de retirarmos o montante do FNE dos fluxos de investimentos, da mesma forma que na seção anterior, realocaremos tal montante em gastos correntes do governo de forma proporcional a todos os estados, o que representa uma elevação de 0,47\% na demanda governamental de cada UF. Esse cenário contemplaria um formato alternativo à transferência de renda inter-regional aplicada pelo FNE. Enquanto no mecanismo original do FNE os R $\$ 4,1$ bilhões do Fundo são alocados em 11 estados, exercício contra-factual proposto, os recursos são alocados entre todas as UFs do Brasil.

Embora representem o mesmo percentual, o montante repassado e sua representatividade no PIB são diferentes entre as UFs. São Paulo, por exemplo, seria o estado com maior valor transferido ( $\mathrm{R} \$ 842$ milhões), embora isso corresponda a apenas $0,07 \%$ do PIB estadual em 2011. Por outro lado, temos casos como o de Roraima, em que os R $\$ 20$ milhões recebidos representam $0,30 \%$ do PIB estadual (Tabela 7). Ademais, os impactos gerados pelos repasses podem estar relacionados ao peso da demanda do governo exerce sobre o PIB de cada estado. 
Tabela 7 - Montante Repassado aos Gastos Correntes do Governo e Participações Governamentais no PIB: Cenário de Realocação do FNE

\begin{tabular}{|c|c|c|c|}
\hline UF & $\begin{array}{c}\text { Repasse } \\
\text { (R\$ milhões) }\end{array}$ & $\begin{array}{c}\text { (\%) do repasse } \\
\text { no PIB }\end{array}$ & $\begin{array}{l}\text { (\%) do governo } \\
\text { no PIB }\end{array}$ \\
\hline Rondônia & 36,53 & 0,15 & 32,28 \\
\hline Acre & 18,38 & 0,22 & 48,10 \\
\hline Amazonas & 63,90 & 0,11 & 23,12 \\
\hline Roraima & 20,19 & 0,30 & 64,20 \\
\hline Pará & 98,94 & 0,11 & 23,36 \\
\hline Amapá & 22,30 & 0,26 & 54,67 \\
\hline Tocantins & 30,69 & 0,19 & 39,61 \\
\hline Maranhão & 76,50 & 0,17 & 35,62 \\
\hline Piauí & 46,01 & 0,20 & 42,48 \\
\hline Ceará & 117,23 & 0,15 & 32,01 \\
\hline Rio Grande do Norte & 62,46 & 0,17 & 36,68 \\
\hline Paraíba & 65,22 & 0,20 & 42,26 \\
\hline Pernambuco & 145,76 & 0,16 & 33,29 \\
\hline Alagoas & 46,76 & 0,16 & 35,04 \\
\hline Sergipe & 42,23 & 0,16 & 34,68 \\
\hline Bahia & 195,06 & 0,13 & 28,62 \\
\hline Minas Gerais & 329,41 & 0,09 & 20,15 \\
\hline Espírito Santo & 77,45 & 0,09 & 19,23 \\
\hline Rio de Janeiro & 538,20 & 0,12 & 26,40 \\
\hline São Paulo & 842,02 & 0,07 & 15,22 \\
\hline Paraná & 180,80 & 0,08 & 17,68 \\
\hline Santa Catarina & 120,39 & 0,08 & 17,52 \\
\hline Rio Grande do Sul & 214,64 & 0,09 & 20,28 \\
\hline Mato Grosso do Sul & 58,98 & 0,12 & 26,08 \\
\hline Mato Grosso & 62,78 & 0,10 & 21,79 \\
\hline Goiás & 106,48 & 0,10 & 21,67 \\
\hline Distrito Federal & 487,36 & 0,37 & 79,23 \\
\hline
\end{tabular}

Utilizando o fechamento de longo prazo, simulamos o cenário em que os recursos do FNE são destinados, alternativamente, aos gastos correntes do governo. Decompusemos os resultados da simulação a fim de isolarmos os impactos devidos à eliminação do FNE, semelhantes aos da seção anterior, e os impactos associados aos repasses para os gastos do governo. Os efeitos líquidos correspondem à soma das duas partes anteriores desses dois efeitos isolados. 
Tabela 8 - Impactos de Longo Prazo sobre Variáveis Macroeconômicas: Cenário de realocação do FNE (em $\Delta \%)$

\begin{tabular}{lccc}
\hline \multicolumn{1}{c}{ Variável } & Retirada do fundo & $\begin{array}{c}\text { Realocação em gastos } \\
\text { correntes }\end{array}$ & Efeito líquido \\
\hline PIB real & $-0,19$ & 0,03 & $-0,16$ \\
Consumo real das famílias & $-0,47$ & 0,24 & $-0,23$ \\
Gastos reais com investimento & $-0,39$ & 0,06 & $-0,33$ \\
Volume de exportações & 0,79 & $-0,98$ & $-0,19$ \\
Volume de importações & $-0,67$ & 0,63 & $-0,04$ \\
Índice de preços do PIB & $-0,41$ & 0,64 & 0,23 \\
\hline
\end{tabular}

Fonte: Elaboração própria.

Em relação a 2011, a eliminação do Fundo, como já discutido, ao reduzir a demanda por investimentos, implicaria em uma redução do PIB e do bem estar das famílias. Com a diminuição da demanda nacional, sobretudo nordestina, os produtores buscariam novos compradores, o que implicaria em uma elevação de exportações, tudo conforme a simulação anterior. Porém, ao recolocarmos os recursos do FNE na economia através da expansão dos gastos correntes do governo, os impactos iriam em direção oposta à verificada anteriormente. Enquanto o PIB cresceria em $0,03 \%$, o consumo das famílias em $0,24 \%$ e os gastos do investimento em $0,06 \%$, as exportações se reduziriam em $0,98 \%$, com um aumento das importações em $0,63 \%$. Todavia, o efeito líquido dessa alternativa de política revela ainda uma redução da absorção doméstica e queda do PIB, acompanhada de uma deterioração da balança comercial na margem. Estes resultados indicam de que o atual mecanismo de operação do FNE é comparativamente indutor de atividade econômica, quando se considera como alocação alternativa a forma como o governo aloca, em média, seus gastos correntes. 
Figura 11 - Índice de Gini do PIB: Cenário de Realocação do FNE

0,5885

0,5880

0,5875

0,5870

0,5865

0,5860

0,5855

0,5850

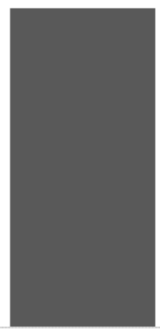

Cenário Base

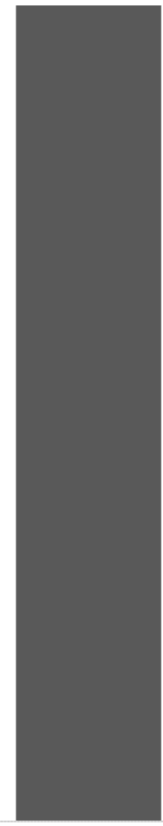

Retirada do fundo

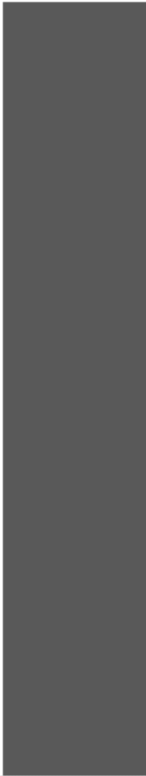

Realocação em gastos correntes

Fonte: Elaboração própria.

Figura 12 - Índice de Williamson do PIB per capita: Cenário de Realocação do FNE 0,4305

0,4300

0,4295

0,4290

0,4285

0,4280

0,4275

0,4270

0,4265

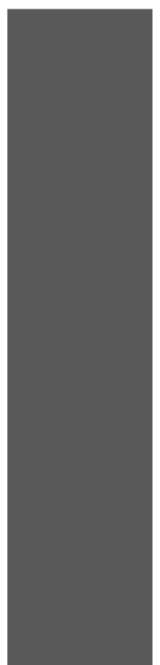

Retirada do fundo

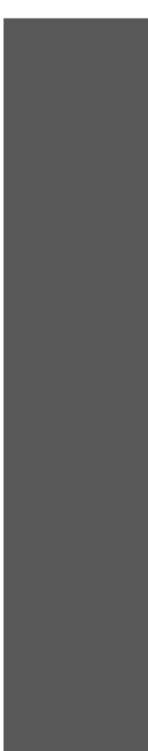

Realocação em gastos correntes

Fonte: Elaboração própria. 
Calculamos também o Índice de Gini Locacional do PIB e o Índice de Williamson do PIB per capita para a comparação do atual mecanismo com forma de gastos alternativa. Notase que a relocação dos recursos do Fundo para gastos do governo geraria maior concentração do PIB em comparação com o verificado atualmente (embora melhorasse um pouco em relação ao que se observaria pela retirada total do Fundo) e maior desigualdade do PIB per capita, uma vez que o Índice de Williamson se eleva para essa situação em comparação ao cenário base, sendo até mais desigual do que o verificado apenas pela retirada do FNE.

Para reforçar o ponto de que o atual mecanismo do FNE estimula mais fortemente a atividade econômica e endereça de maneira mais eficaz o problema regional no Brasil, apresentaremos um conjunto de resultados em que salientamos brevemente os efeitos de curto prazo do FNE. ${ }^{17}$ A Tabela 9 apresenta os resultados comparativos para o PIB nacional e para os indicadores e desigualdade regionais.

Tabela 9 - Impactos Comparativos sobre o PIB Nacional: Curto Prazo versus Longo Prazo

\begin{tabular}{lccc}
\hline \multicolumn{1}{c}{ Variável } & Retirada do fundo & $\begin{array}{c}\text { Realocação em gastos } \\
\text { correntes }\end{array}$ & Efeito líquido \\
\hline PIB real (em $\Delta \%)$ & & & 0,06 \\
Curto Prazo & $-0,02$ & 0,03 & 0,03 \\
Longo Prazo & $-0,19$ & & $-0,16$ \\
& & - & \\
Índice de Gini Locacional* & 0,5866 & - & 0,5865 \\
$\quad$ Curto Prazo & 0,5883 & & 0,5881 \\
Longo Prazo & & - & \\
& & - & 0,4287 \\
Índice de Williamson** & 0,4287 & 0,4295 & 0,4299 \\
$\quad$ Curto Prazo & &
\end{tabular}

* Valor de referência no cenário base $=0,5863$

** Valor de referência no cenário base $=0,4279$

Fonte: Elaboração própria.

\footnotetext{
${ }^{17}$ No fechamento de curto prazo é pressuposto que a população regional encontra-se fixa. Adota-se assim a hipótese que a migração é uma decisão de longo prazo. Ademais, variações no emprego impactam apenas o desemprego regional, não tendo impacto nos salários reais regionais que são constantes neste fechamento. Com esta configuração, a curva de oferta de trabalho se torna perfeitamente elástica no curto prazo, sendo os salários determinados pelo nível de preços ao consumidor nacional. Desta forma, alterações na demanda por trabalho têm impacto direto sobre o desemprego em cada região. Ainda, é pressuposto no fechamento de curto prazo que o investimento e os estoques de capital são fixos por setores e por região, refletindo a hipótese de que os agentes são incapazes de alterar suas decisões de investimento no curto prazo.
} 
No curto prazo, predominam os efeitos pelo lado da demanda, tanto dos gastos com a aquisição de bens de capital como com gastos correntes do governo. A diferença entre os resultados dá-se, sobretudo, por diferenças entre os efeitos multiplicadores dos setores ativados e as respectivas dependências externas que geram níveis distintos de vazamento. No caso de nossa simulação, observa-se que os gastos do governo apresentam capacidade relativamente maior de promover o crescimento no curto prazo. Todavia, tanto para o FNE como para a demanda do governo os efeitos sobre as disparidades regionais são marginais.

No longo prazo, o aumento do estoque de capital produtivo gera impactos importantes pelo lado da oferta, fazendo com que os efeitos dos investimentos do FNE sejam mais relevantes tanto para o crescimento econômico como para a redução das disparidades regionais no Brasil.

\section{Conclusões}


O FNE foi criado em 1988 com o objetivo de estimular a economia do Nordeste brasileiro e diminuir as desigualdades regionais entre tal região e as demais regiões do País. Para isso, o FNE empresta dinheiro a taxas subsidiadas com o intuito de expandir o estoque de capital da região.

Dentre os estudos realizados para se avaliar os FCs no Brasil, há uma carência de análises de impacto em um contexto integrado, que considerem maior interdependência comercial entre as regiões e mobilidade dos fatores de produção. Nesse sentido, aplicamos um modelo IEGC para avaliar os impactos sistêmicos do FNE. Nossas simulações sugerem que o Fundo possui um papel importante no estímulo à atividade econômica e na redução das assimetrias regionais no País. Ao eliminarmos os fluxos de investimentos associados ao FNE, observamos queda no PIB, concentração da produção e aumento da desigualdade do PIB per capita pelo território nacional. Além disso, os estados nordestinos seriam os mais afetados, sobretudo Sergipe, Maranhão e Ceará, uma vez que se verificam maiores quedas de produção, investimento e exportações naquela porção do País, além de pressão migratória para outras regiões.

Ao compararmos a utilização dos recursos do FNE destinados a investimentos produtivos com sua alocação alternativa, destinando-os a gastos correntes do governo, percebese que, no longo prazo, os efeitos associados ao aumento de estoque de capital estimulariam mais fortemente a atividade econômica. Em outras palavras, dada a natureza dos gastos simulados do FNE, o Fundo teria também um efeito de longo prazo ao crescimento econômico que a demanda tradicional do governo, além de endereçar mais eficaz o problema regional no Brasil. Ao se observar também alguns efeitos de curto prazo, observa-se que ambos geram estímulos de demanda, embora efeitos sobre as disparidades regionais sejam marginais. Estes resultados são importantes para uma discussão mais ampla sobre estratégias de crescimento e promoção da coesão regional, uma vez que sugerem que efeitos de longo prazo estariam mais fortemente atrelados a políticas que, não apenas incentivem a demanda local, mas também estimulem o aumento da capacidade produtiva regional.

\section{Referências Bibliográficas}


ALMEIDA JUNIOR, M.; RESENDE, G. M.; SILVA A. M. Distribuição espacial dos fundos constitucionais de financiamento do Nordeste, Norte e Centro-Oeste. Revista de Economia, v. 33, n. 2, p. 115-137, 2007.

ÁLVAREZ-MARTÍNEZ, M. The Effects of European Structural Funds in the Spanish Regions Using CGE Models: a review. Investigaciones Regionales, n. 29, p. 129-138, 2014.

BARROS, A. Desigualdades Regionais no Brasil, Rio de janeiro: Elsevier, 2011.

BRASIL. Câmara dos Deputados. Nova Delimitação do Semi-Árido Brasileiro. Brasília, DF: Câmara dos Deputados, 2007.2 Disponível em: <http://bd.camara.gov.br/bd/handle/bdcamara/1604> Acesso em: 25 set. 2015.

BRASIL. Lei $\mathrm{n}^{\circ}$ 7.827, de 27 de Setembro de 1989. Regulamenta o art. 159, inciso I, alínea c, da Constituição Federal, institui o Fundo Constitucional de Financiamento do Norte - FNO, o Fundo Constitucional de Financiamento do Nordeste - FNE e o Fundo Constitucional de Financiamento do Centro-Oeste - FCO, e dá outras providências. Diário Oficial da República Federativa do Brasil, Brasília, DF, set. 1989. Disponível em: <http://www.planalto.gov.br/ccivil_03/leis/17827.htm >. Acesso em: 25 set. 2015.

BRASIL. Ministério da Integração Nacional. Nova Delimitação do Semi-Árido Brasileiro. Brasília, DF, 2007.2 Disponível em: http://www.asabrasil.org.br/UserFiles/File/cartilha_delimitacao_semi_arido.pdf> Acesso em: 25 set. 2015.

CAMPOS, R.; HADDAD, E. Avaliação dos impactos espaciais do Sistema Viário OesteBahia: uma abordagem a partir da modelagem de equilíbrio geral computável. Revista Brasileira de Economia de Empresas, n. 16, v. 2, p. 25-47, 2016.

CARDENETE, M.; DELGADO, M. Analysis of the Impact of the European Funds in Andalusia in 2007-2013 Using a General Equilibrium Model. Modern Economy, v. 4, n. 6, p. 448-452, 2013.

CARVALHO, A.; LALL, S.; TIMMINS, C. Decisão locacional de novos estabelecimentos e o papel dos fundos constitucionais de financiamento. In: CARVALHO, A. et al. Ensaios de economia regional e urbana. Brasília: Ipea, 2008.

CARVALHO, N.; REGE, S.; FORTUNA, M.; ISIDRO, E.; EDWARDS-JONES, G. Estimating the impacts of eliminating fisheries subsidies on the small island economy of the Azores. Ecological Economics, v. 70, n. 10, p. 1822-1830, 2011.

CRAVO, T.; RESENDE, G. The Impact of Brazilian Regional Development Funds on Regional Economic Growth: A spatial panel approach. In: 54th ERSA Congress, 2014.

FERREIRA, M.; MENDES, F. Impactos do fundo constitucional de financiamento do norte (FNO) sobre a agricultura paraense - 1990 a 1999. In: Congresso da sociedade brasileira de economia, administração e sociologia rural, 2003.

FORTUNA, M.; SILVA, F.; MEDEIROS, A. A CGE approach to measuring the impacts of EU structural funds in a small open economy. Papers in Regional Science, v. 95, n. 3, p. 507-538, 2014. 
HADDAD, E. Regional inequality and structural changes: lessons from Brazilian experience. Aldershot: Ashgate, 1999.

HADDAD, E. Retornos crescentes, custos de transporte e crescimento regional. 2004. Tese (Livre Docência). 207 f. Faculdade de Economia, Administração e Contabilidade, Universidade de São Paulo, São Paulo, 2004.

HADDAD E.; AZZONI, C. Trade Liberalization and Location: Geographical Shifts in the Brazilian Economic Structure. In: J. J. M. Guilhoto e G. J. D. Hewings (eds), Structure and Structural Change in the Brazilian Economy. Aldershot, Ashgate, 2001.

HADDAD, E.; HEWINGS, G. Market imperfections in a spatial economy: some experimental results. The Quarterly Review of Economics and Finance, v. 45, p. 476-496, 2005.

HADDAD, E.; PEROBELlI, F.; DOMINGUES, E; AGUIAR, M. Avaliação dos Impactos Econômicos das Políticas de Infraestrutura de Transportes no Brasil: Uma Aplicação a duas Rodovias Federais em Minas Gerais. Cadernos do Banco de Desenvolvimento de Minas Gerais. Banco de Desenvolvimento de Minas Gerais, v. 16, p. 29-72, 2008.

MENEZES, A.; FORTUNA, M.; SILVA, F.; VIEIRA, J. Computable general equilibrium models: A literature review. Working Paper n. 6. Centro de Estudos de Economia Aplicada do Atlântico, 2006.

MONTEIRO, J. Avaliação da utilização dos recursos do fundo constitucional de financiamento do norte no estado de Roraima. 2011. 122 f. Dissertação (Mestrado). Universidade Federal do Rio Grande do Sul, Porto Alegre, 2011.

OLIVEIRA, H.; DOMINGUES, E. Considerações sobre o impacto dos Fundos Constitucionais de Financiamento do Norte e do Centro-Oeste na redução da desigualdade regional no Brasil. Anais do XXXIII Encontro Nacional de Economia, 2005.

PETER, M.; HORRIDGE, M.; MEAGHER, G.; NAQVI, F.; PARMENTER, B. The Theoretical Structure of MONASH-MRF. Working Paper n. 85, IMPACT Project, Monash University, 1996.

PORSSE, A. Competição tributária regional, externalidades fiscais e federalismo no Brasil: uma abordagem de equilíbrio geral computável. 2005. 146 f. Tese (Doutorado). Universidade Federal do Rio Grande do Sul, Porto Alegre, 2005.

RESENDE, G. Measuring micro- and macro-impacts of regional development policies: the case of the FNE Industrial loans in Brazil, 2000-2006. Regional Studies, v.48, n. 4, p. 646-664, 2012.

RESENDE, G.; SILVA, D.; SILVA FILHO, L. Avaliação dos efeitos econômicos dos Fundos Constitucionais de Financiamento do Nordeste (FNE), do Norte, (FNO) e do Centro-Oeste (FCO): Uma análise por tipologia da PNDR entre 1999 e 2011. Brasília: Ipea, 2015.

SOARES, R.; SOUSA, J.; PEREIRA NETO, A. Avaliação de impactos do FNE no emprego, na massa salarial e no salário médio em empreendimentos financiados. Revista Econômica do Nordeste, v. 40, n. 1, p. 217-234, 2009. 